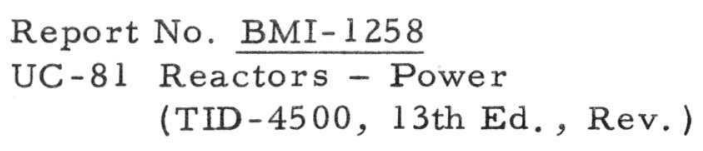

Contract No. W-7405-eng-92

\title{
STUDIES OF UPPER-PLENUM COOLANT CIRCULATION IN A QUARTER-SCALE AIR-FLOW MODEL OF THE PWR
}

Alexander R. Orban

Herbert R. Hazard

March 18, 1958 


\section{DISCLAIMER}

This report was prepared as an account of work sponsored by an agency of the United States Government. Neither the United States Government nor any agency Thereof, nor any of their employees, makes any warranty, express or implied, or assumes any legal liability or responsibility for the accuracy, completeness, or usefulness of any information, apparatus, product, or process disclosed, or represents that its use would not infringe privately owned rights. Reference herein to any specific commercial product, process, or service by trade name, trademark, manufacturer, or otherwise does not necessarily constitute or imply its endorsement, recommendation, or favoring by the United States Government or any agency thereof. The views and opinions of authors expressed herein do not necessarily state or reflect those of the United States Government or any agency thereof. 


\section{DISCLAIMER}

Portions of this document may be illegible in electronic image products. Images are produced from the best available original document. 


\section{TABLE OF CONTENTS}

Page

ABSTRACT

INTRODUCTION . . . . . . . . . . . . . . . . . . . . . . . . . . . . 1

DESCRIPTION OF THE QUARTER-SCALE AIR-FLOW MODEL

$\mathrm{OF}$ THE PWR . . . . . . . . . . . . . . . . . . . . . . . . . . . . . 2

General Description of Model . . . . . . . . . . . . . . . . . 2

STUDIES OF FLOW IN THE UPPER PLENUM OF THE QUARTER-SCALE

FLOW MODEL WITH HOLD-DOWN BARREL NO. 1 . . . . . . . . . . . . 2

Description of the Upper Plenum . . . . . . . . . . . . . . . 2

OUTLINE OF UPPER-PLENUM FLOW STUDIES . . . . . . . . . . . . . . 5

RESULTS OF UPPER-PLENUM STUDIES WITH HOLD-DOWN

BARREL NO. 1. . . . . . . . . . . . . . . . . . . . . . . . . 10

Air Distribution to Holes in Hold-Down Barrel No. 1 . . . . . . . . . . 10

Air Circulation in the Upper Plenum With Hold-Down Barrel No. 1. . . . 14

Velocities and Directions of Flow at the Inner Surface of the Upper

Dome With Hold-Down Barrel No. 1. . . . . . . . . . . . . . . . . 18

STUDIES OF FLOW IN THE UPPER PLENUM OF THE QUARTER-SCALE

MODEL WITH HOLD-DOWN BARREL NO. 2. . . . . . . . . . . . . . . . 25

Description of Hold-Down Barrel No. 2 . . . . . . . . . . . . . . . 25

Air Circulation in the Upper Plenum of the Quarter-Scale Model With

Hold-Down Barrel No. 2. . . . . . . . . . . . . . . . . . . . 25

Velocities and Directions of Flow at the Inner Surface of the Upper

Dome With Hold-Down Barrel No. 2 . . . . . . . . . . . . . . . . 31

Velocities and Directions of Flow in the Space Between Hold-Down

Barrel No. 2 and the Pressure Vessel of the Quarter-Scale Model . . . 31

Pressure Loss for Hold-Down Barrel No. 2 . . . . . . . . . . . . . . 37

Pressure Drop at Outlet Nozzle With Hold-Down Barrel No. 2 . . . . . . 42

ACKNOWLEDGMENTS . . . . . . . . . . . . . . . . . . . . . . . . . . 42 


\title{
STUDIES OF UPPER-PLENUM COOLANT CIRCULATION IN A QUARTER-SCALE AIR-FLOW MODEL OF THE PWR
}

\author{
Alexander R. Orban and Herbert R. Hazard
}

Air-flow studies were run in a quarter-scale flow model of the PWR to determine distribution of flow throughout the upper-plenum region with two different hold-down-barrel designs. With each hold-down barrel, flow paths were determined for operation with four loops, three loops, two opposed loops, and two adjacent loops. Exploration of flow patterns and velocities throughout the upper plenum showed that circulation of coolant throughout the upper plenum was satisfactory with either of the hold-down barrels investigated.

\section{INTRODUCTION}

This report presents the results of air-flow studies to determine flow patterns and velocities in the upper plenum of the PWR. Studies were carried out in a quarterscale flow model of the reactor. The model was designed by the Atomic Energy Commission's Bettis Laboratory, operated by the Westinghouse Electric Corporation, and was constructed by the Westinghouse Aviation Gas Turbine Division.

The upper plenum is a space above the core having a height about twice the inside diameter of the pressure vessel. Coolant enters from the core, at the bottom of the space, flows upward, and passes through openings in the hold-down barrel to a narrow annular space between the hold-down barrel and the pressure vessel. In this space, it flows downward to the four outlets, which are located near the bottom of the space.

This is the fifth report covering flow studies in the quarter-scale flow model. Previous reports were:

BMI-1141 - "Studies of Flow Distribution in the Core of a Quarter-Scale Flow Model of the PWR Reactor"

BMI-1172 - "Studies of Mixing in the Lower Plenum of a Quarter-Scale Flow Model of the PWR Reactor"

BMI-1198 - "Model Studies of Flow in the Thermal-Shield Passages of the PWR Reactor"

BMI-1229 - "Supplementary Model Studies of Flow Distribution in the Core of the PWR Reactor". 


\title{
DESCRIPTION OF THE QUARTER-SCALE AIR-F LOW MODEL OF THE PWR
}

\author{
General Description of Model
}

The quarter-scale flow model was designed to study flow conditions throughout the PWR, with the exception of those within the fuel assemblies, which were simulated in the model with orificed tubes. Air was used to simulate prototype coolant flow. Reynolds numbers in the model ranged from about 400,000, in inlet ducts, to about 8,000 in thermal-shield passages. For all studies described in this report, dynamic similarity between model and prototype can be assumed. Except for the core structure, all parts of the model were accurately scaled from the prototype.

Figure $l$ is an exterior view of the model. Four centrifugal blowers at the left supplied air for tests, and the large manometer panel at the right was used to record pressures throughout the model. Piping approaching the inlets was made similar to that for the prototype, and provision was made to equalize flow in inlets and outlets. For tests simulating operation with two or three loops, the inactive inlets and outlets were blocked off with plates installed between piping flanges.

Figure 2 is a vertical cross section of the model showing the general arrangement of the inlets and outlets, the flow baffle, the core, the control-rod guides, and the hold-down barrel. The model was constructed of aluminum, stainless steel, and glass fiber-reinforced plastic.

Air, simulating the reactor coolant, entered through two or more of the four inlets at the bottom of the model. About 85 per cent of the air flowed upward through the perforated flow baffle under the core, and 15 per cent was diverted around the flow baffle and through the thermal-shield coolant passages. Air was discharged from the shield passages under the core, where it mixed with air coming through the flow baffle and passed upward through the core and into the upper plenum. From the upper plenum, it passed into the space between the pressure vessel and the hold-down barrel, and from this space it was discharged through two or more outlet ducts.

STUDIES OF FLOW IN THE UPPER PLENUM OF THE QUARTERSCALE FLOW MODEL WITH HOLD-DOWN BARREL NO. 1

\section{Description of the Upper Plenum}

The upper plenum is the space above the core, as shown in Figure 2. It contains 32 control-rod guides, which are mounted directly above the 32 fuel clusters in the seed region, and a hold-down barrel, which distributes flow in the upper plenum and serves as a structural member to hold the core in position. Four pairs of conduits carrying pressure-tap lines from the model core pass through the upper plenum. 


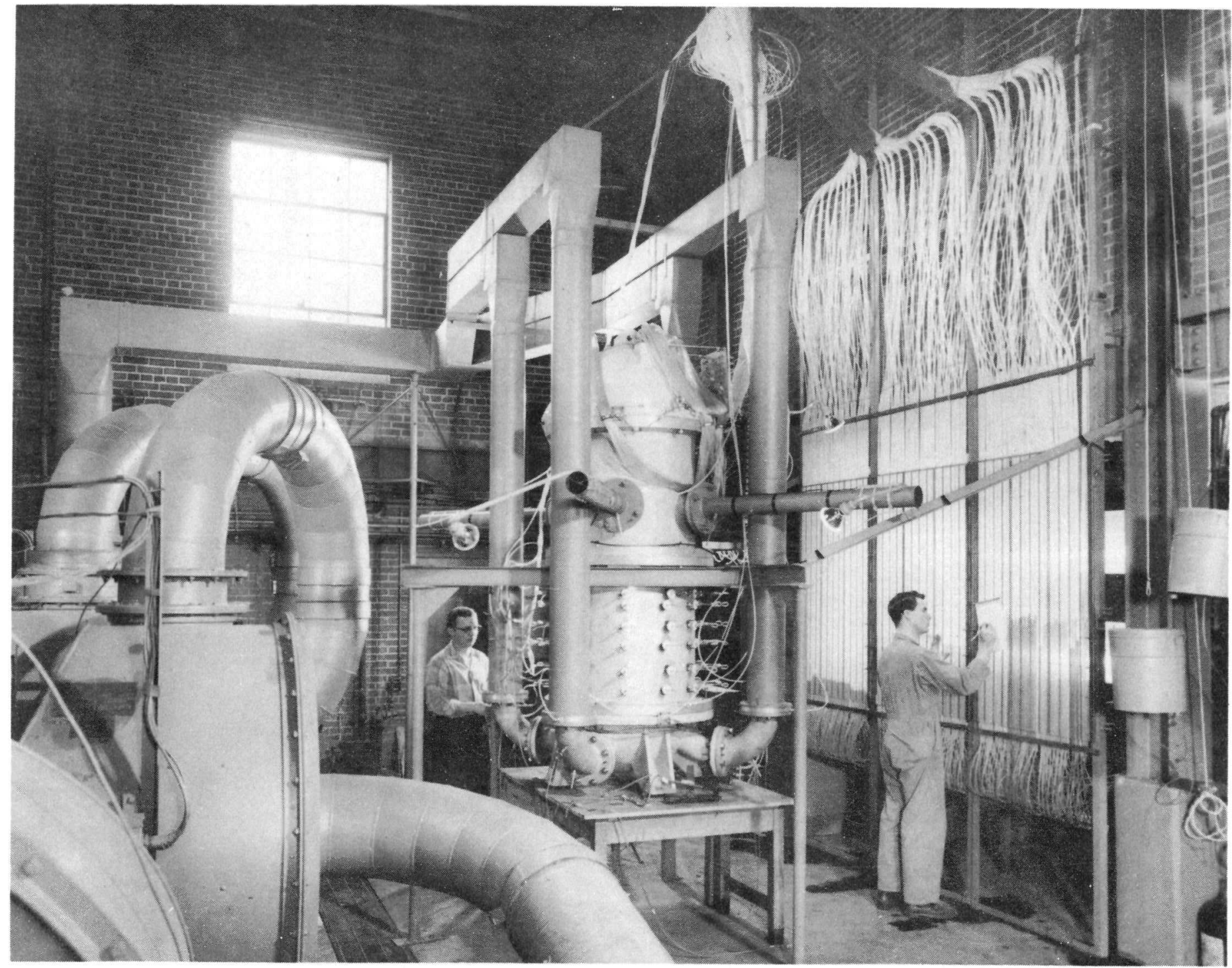

FIGURE 1. PHOTOGRAPH OF QUARTER-SCALE FLOW MODEL OF THE PWR INSTALLED FOR AIR-FLOW STUDIES 


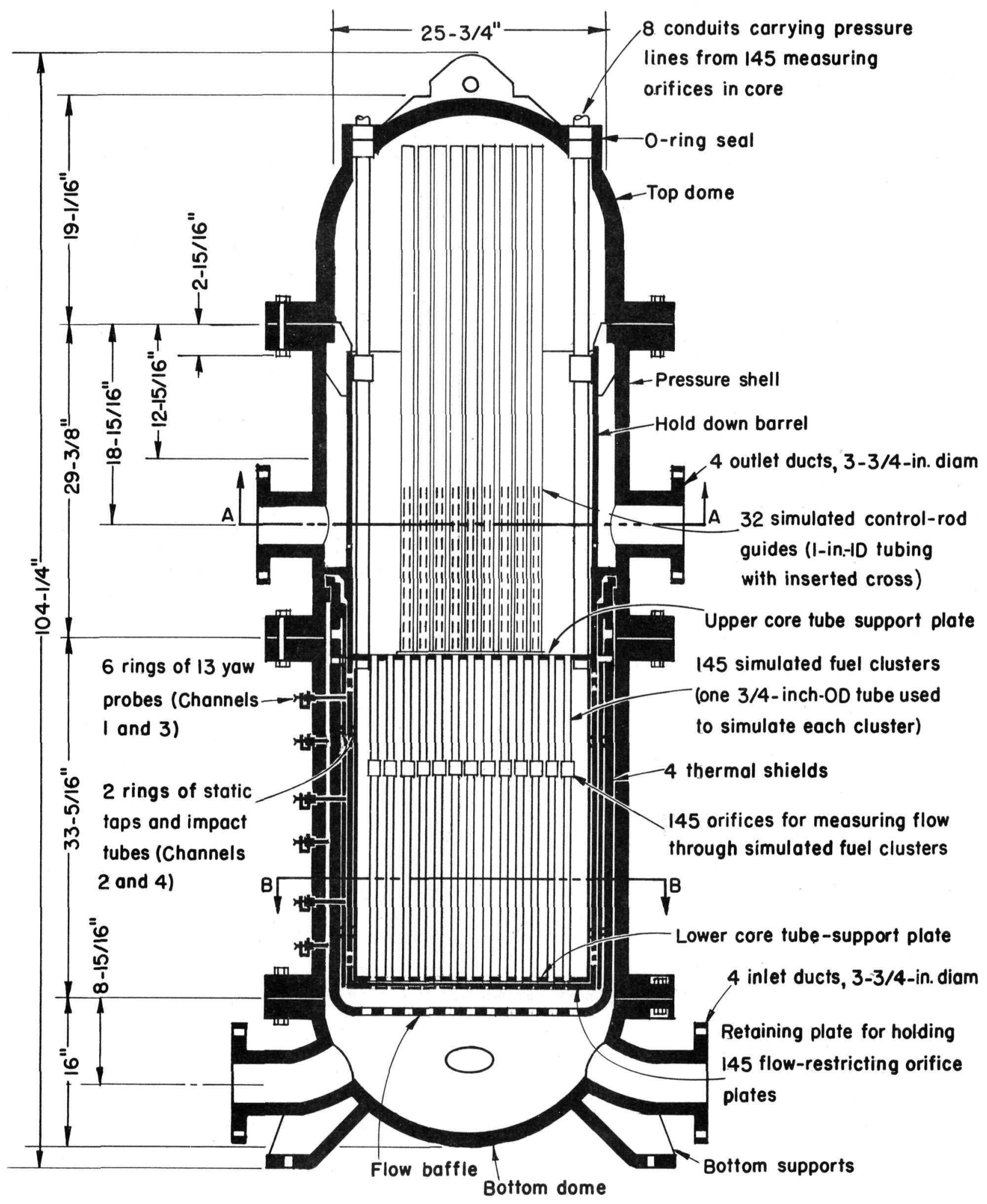

FIGURE 2. VER TICAL SECTION OF THE QUAR TER-SCALE FLOW MODEL 
These would not be present in the prototype. However, the flow areas in the plenum are so large that no appreciable effect of the se obstructions would be expected.

Figure 3 is a section of the model through the upper plenum showing the pressure vessel, Hold-Down Barrel No. 1, and the control-rod guides.

Figure 4 shows the control-rod guide assembly. The guides are supported $1 / 2$ in. above the outlet ends of the seed clusters by a grid. Each guide has 40 slots. Air leaving the seed clusters can pass around the ends of the guides, or enter the guides and pass out through these slots. The flow areas are sufficient so that restriction of flow from the seed assemblies is negligible. Flow from the assemblies discharging into the space enclosed by the guides must pass out through the small spaces between the guides. This results in a small pressure differential across the guides, with resulting bending forces on the guides.

Figure 5 shows Hold-Down Barrel No. 1. This hold-down barrel has 28 holes through which the air passes. Four of the large holes at the bottom of the barrel are in line with the four outlets.

Figure 6 is a photograph of the upper plenum with the top dome removed, showing the control-rod guides and Hold-Down Barrel No. 1 in place. The top of the hold-down barrel is flush with the top of the pressure-vessel flange, and there is an annular space between the barrel and the pressure vessel. Three of the four pairs of coreinstrumentation conduits can also be seen.

\section{OUTLINE OF UPPER-PLENUM FLOW STUDIES}

Flow patterns and velocities in the upper plenum were studied to as sure that adequate circulation was obtained throughout the upper plenum, and that flow velocities over all exposed surfaces of the pressure vessel and closure head were sufficient to insure uniform temperature distribution. After tests with the first hold-down barrel were completed, a second hold-down barrel of different design was installed and similar tests were run.

To determine the distribution of air entering the 28 holes in the first hold-down barrel, impact and static tubes were installed in the openings to measure velocity through each opening. The percentage of flow through each opening was computed from hole area and velocity, assuming the same orifice coefficient for all openings.

Flow patterns in the upper plenum were traced using titanium tetrachloride smoke. A cotton swab at the end of a metal rod was dipped in the titanium tetrachloride and inserted into the upper plenum through an appropriate opening. The titanium tetrachloride gave off dense white smoke for a period of several minutes, making it possible to trace flow directions. Several Lucite windows were installed in the model to facilitate visual flow tracing. 


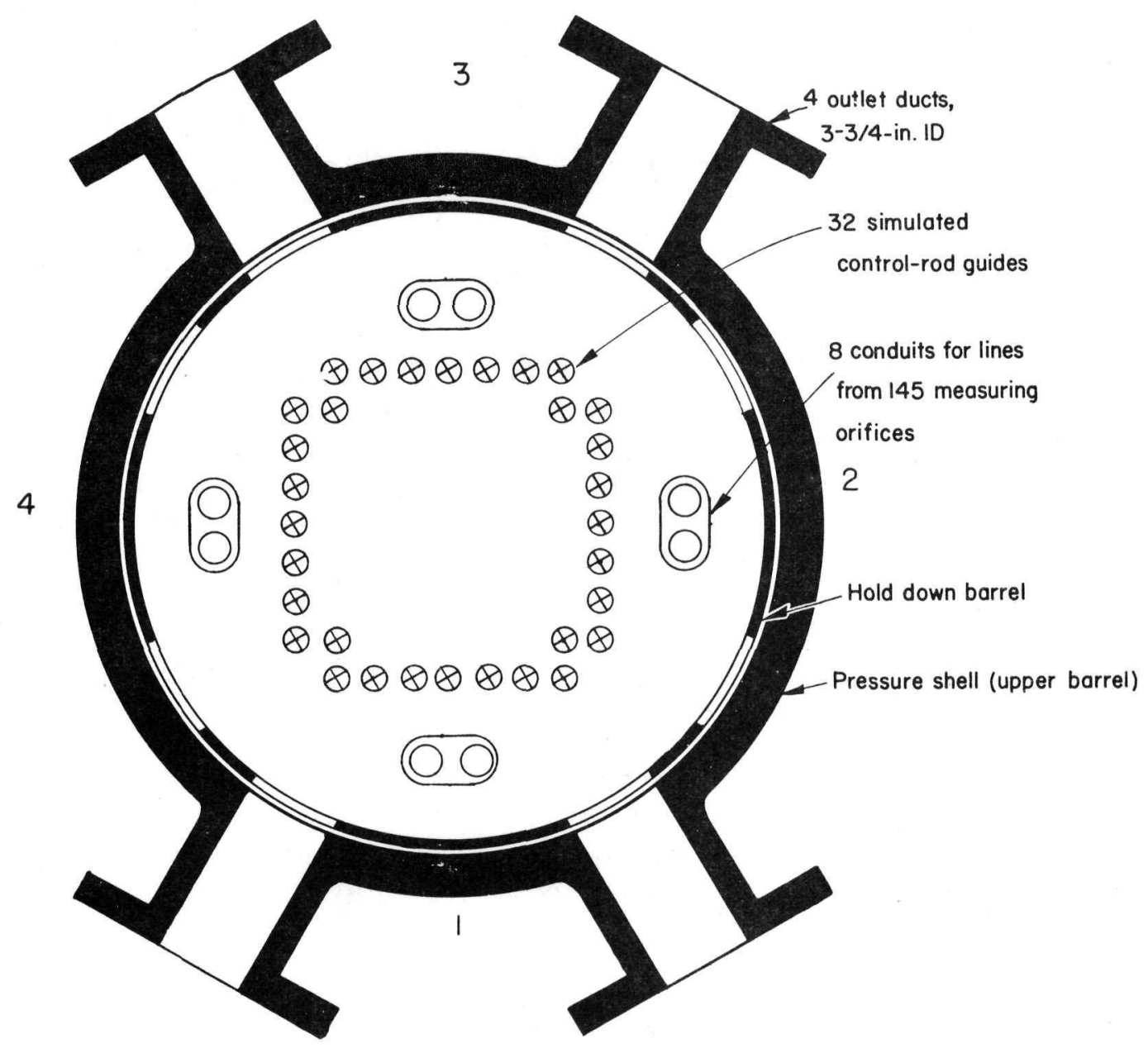

FIGURE 3. HORIZONTAL SECTION THROUGH UPPER PLENUM OF THE QUARTER-SCALE FLOW MODEL 

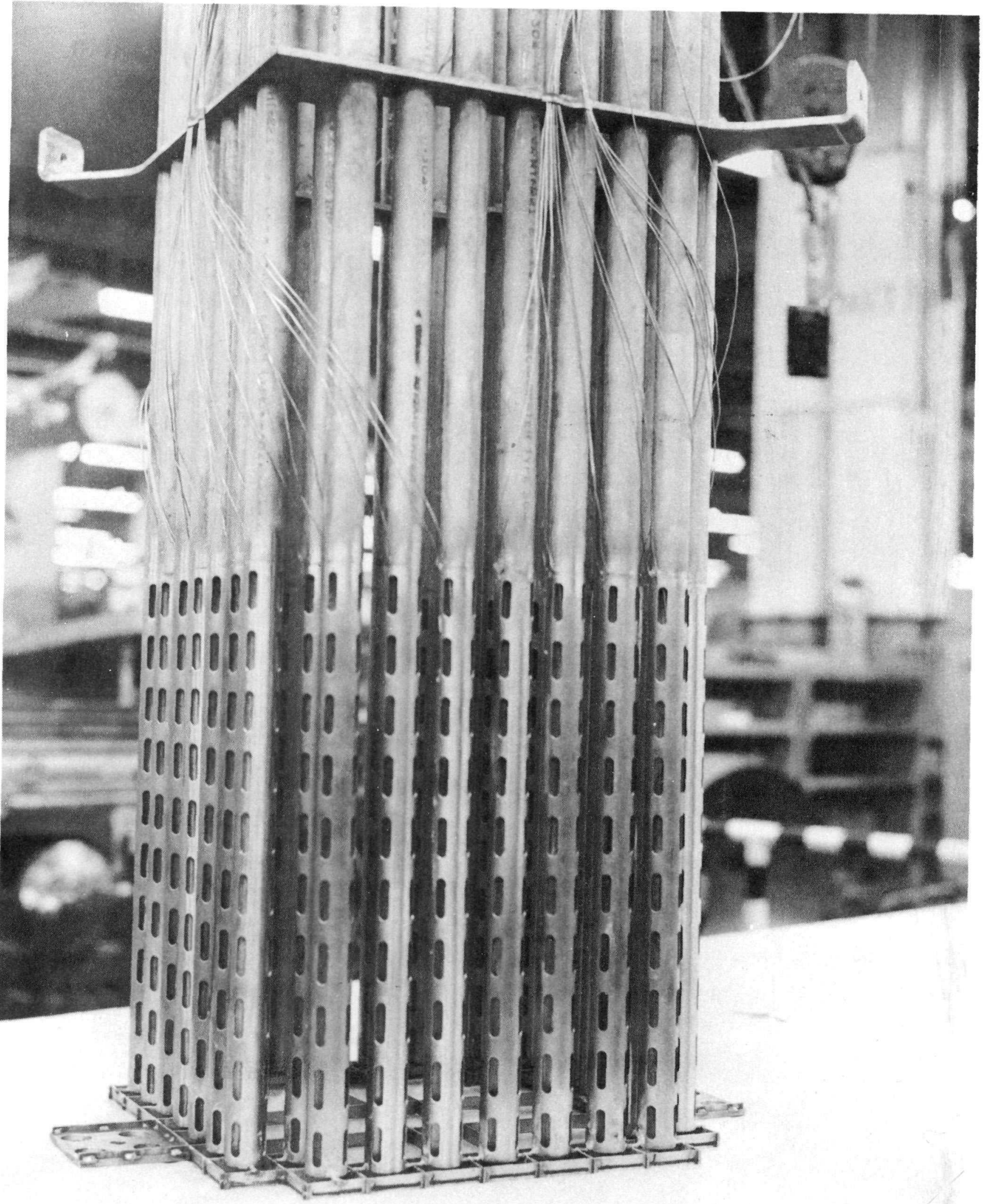

FIGURE 4. PHOTOGRAPH OF CONTROL-ROD GUIDE ASSEMBLY FOR THE QUARTER-SCALE MODEL 


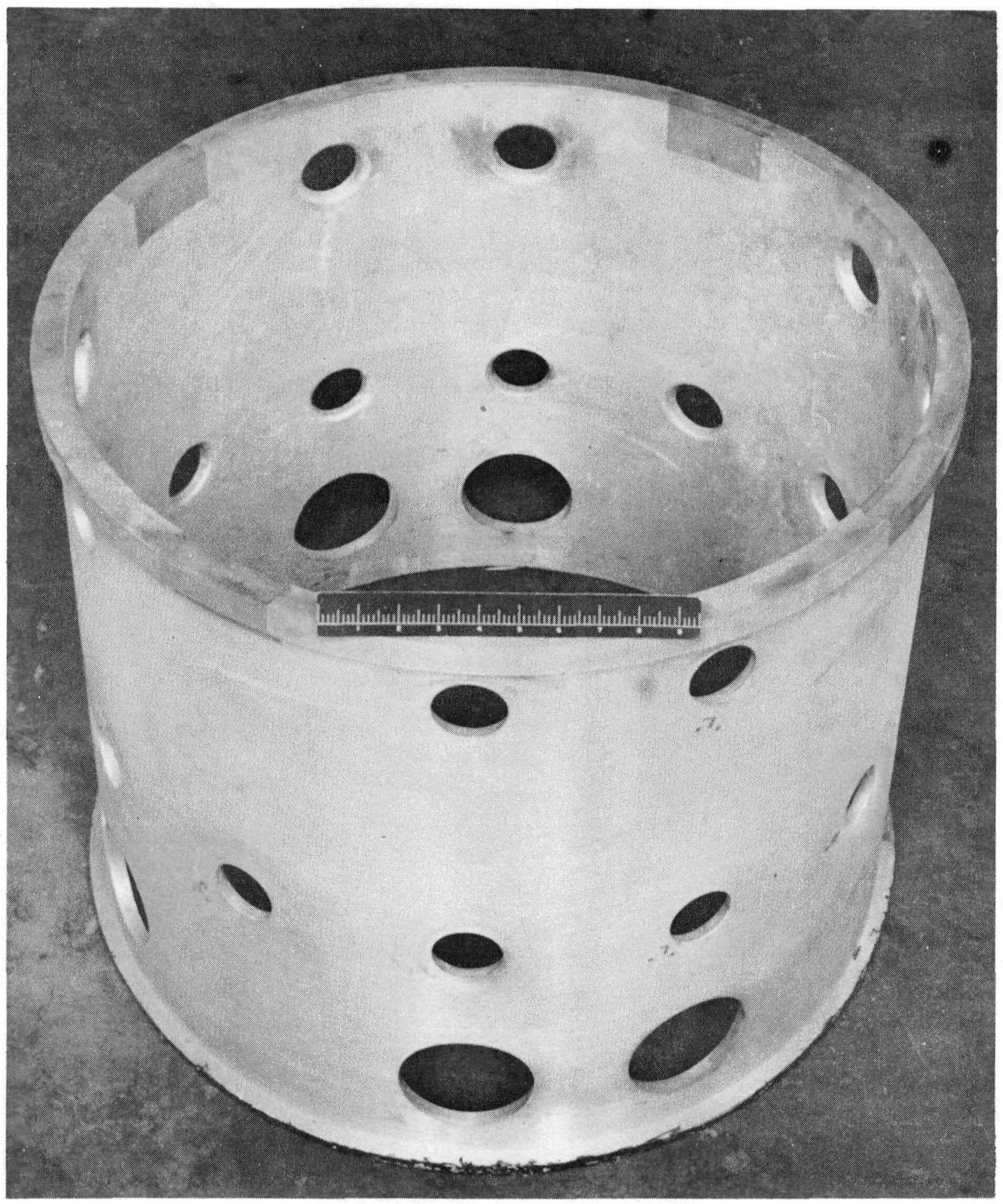

N36119

FIGURE 5. PHOTOGRAPH OF HOLD-DOWN BARREL NO. 1 


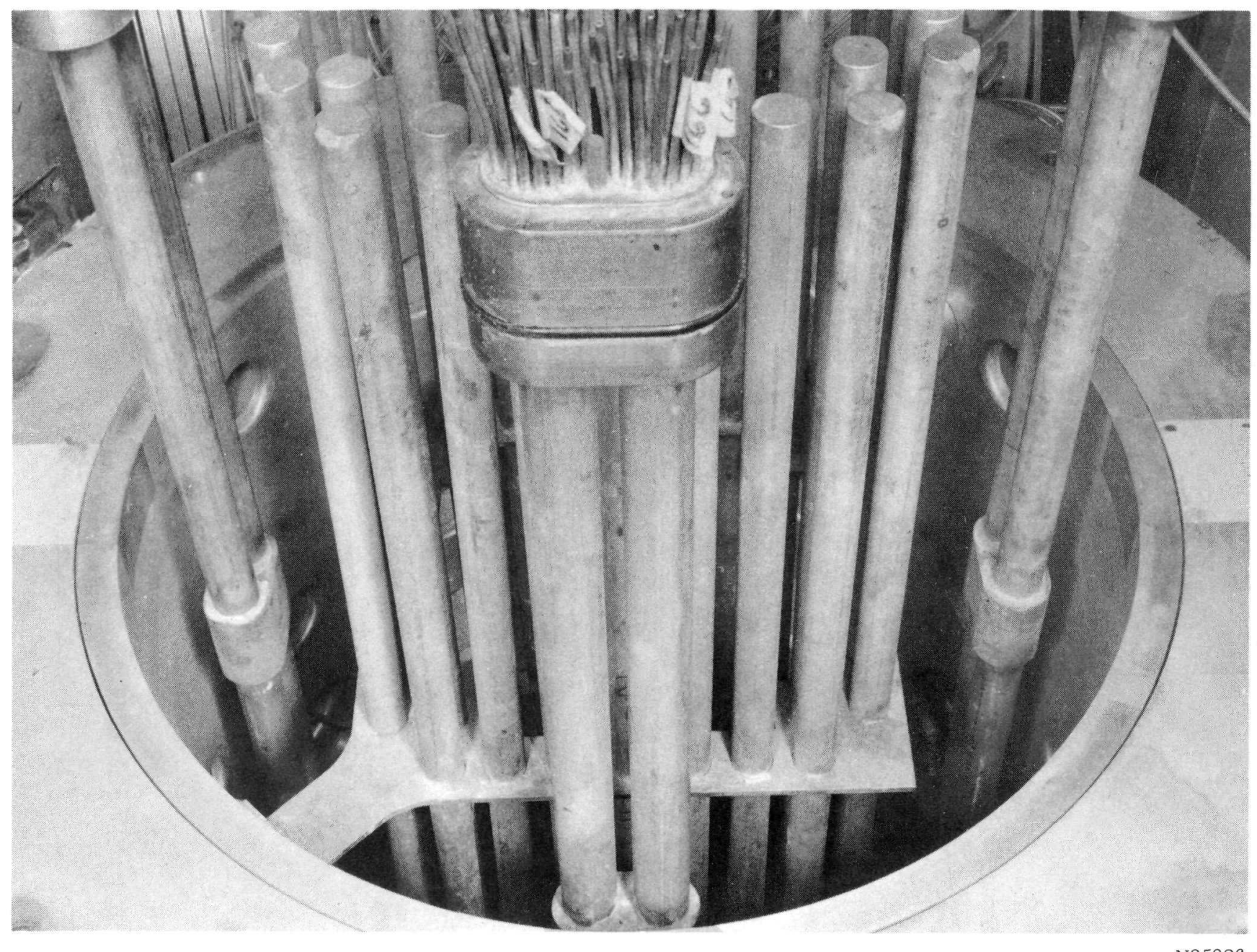

FIGURE 6. PHOTOGRAPH OF HOLD-DOWN BARREL NO. 1 INSTALLED IN THE UPPER PLENUM OF THE QUARTER-SCALE FLOW MODEL 
To determine flow velocities over the inner surface of the pressure vessel, a number of 1/4-in. holes were drilled in the upper dome and in the upper barrel behind the hold-down barrel. Velocities and directions of flow at each of the se locations were measured by inserting a two-hole cylindrical yaw probe into each hole in turn. Velocities down to $2 \mathrm{fps}$ could be mapped with this technique.

For upper-plenum studies, the following air-flow rates were used: four-loop operation, $5.33 \mathrm{lb}$ per sec; three-loop operation, $4.12 \mathrm{lb}$ per sec; and two-loop operation, $3.40 \mathrm{lb}$ per sec. These flow rates are proportional to the coolant-flow rates in the prototype for these operating configurations. Thus, the measured velocities are all proportional to those in the prototype, and can be compared directly for all test conditions with the two hold-down barrels studied. The air velocities in the upper plenum of the model were approximately nine times the corresponding prototype coolant velocities.

\title{
RESULTS OF UPPER-PLENUM STUDIES \\ WITH HOLD-DOWN BARREL NO. 1
}

\author{
Air Distribution to Holes in Hold-Down Barrel No. 1
}

Hold-Down Barrel No. 1, which was shown in Figure 5, served as both a structural member and a flow distributor. Coolant from the upper plenum passed through 28 holes in the hold-down barrel, and through the narrow annular passage between the hold-down barrel and the pressure vessel, to reach the four outlets. The arrangement of holes in the hold-down barrel was selected to provide good circulation of coolant throughout the upper plenum.

Figure 7 is a development of the hold-down barrel, showing the locations of holes, the air velocity through each hole, and the percentage of total model flow passing through each hole for four-loop operation: Velocities ranged from 10 to $174 \mathrm{fps}$ and were highest through holes in line with the four outlets. Of the total coolant flow, 69. 2 per cent entered the four holes in line with outlets, leaving 30.8 per cent to enter the other 24 holes. Values for two holes were estimated because the holes were not accessible for making measurements. Water velocities in the prototype would be smaller than air velocities in the model by a factor of approximately 9.

Figure 8 is a development of Hold-Down Barrel No. 1 showing air velocities through the holes, and flow distribution for three-loop operation. The three holes in line with the three operating outlets passed 63.5 per cent of the total flow, leaving 36.5 per cent for the other 25 holes.

Figure 9 is a development of the hold-down barrel showing test results for operation with two adjacent loops. For this configuration, the two holes in line with the two outlets passed 59 per cent of the total flow, leaving 41 per cent to pass through the other 26 holes. Measurements indicated that no air entered one large hole. A check with titanium tetrachloride smoke verified this, but also revealed a high circumferential velocity behind the hold-down barrel at this location, indicating that coolant circulation was adequate. 



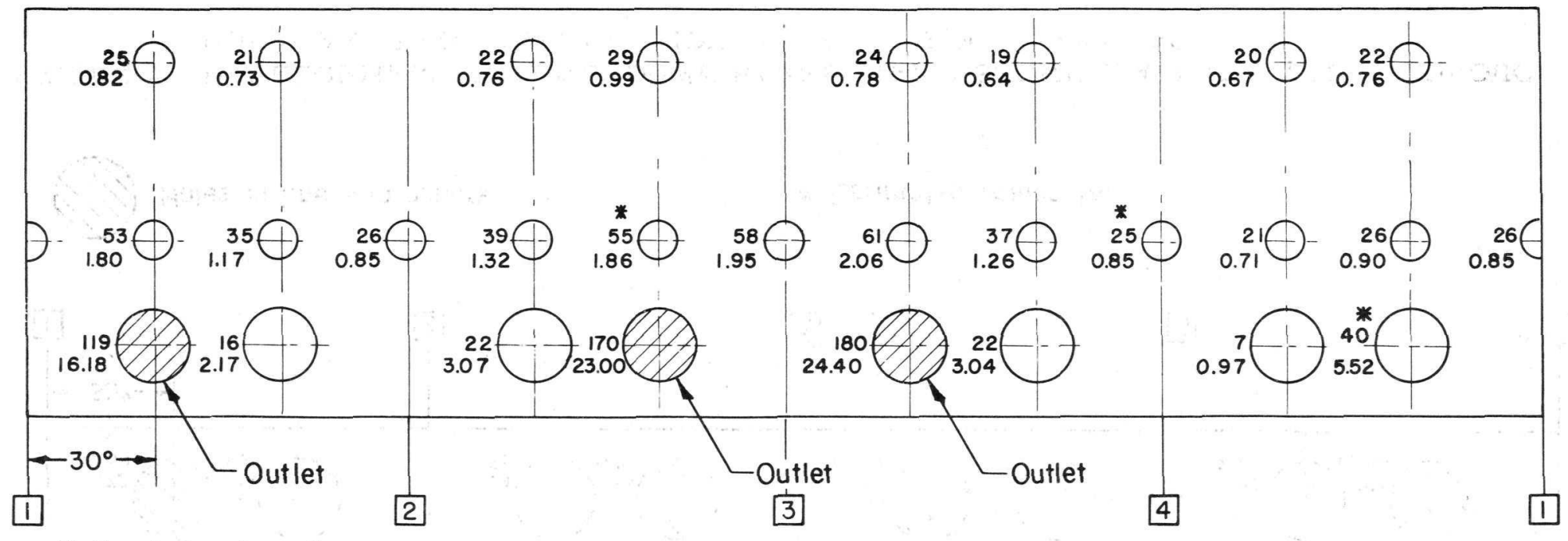

* Estimated values, fps

FIGURE 8. DEVELOPMENT OF HOLD-DOWN BARREL NO. I SHOWING AIR VELOCITIES THROUGH HOLES AND FLOW DISTRIBUTION FOR THREE-LOOP OPERATION

Upper numbers show air velocity through each hole, fps.

Lower numbers show percentage of total flow passing through each hole. 


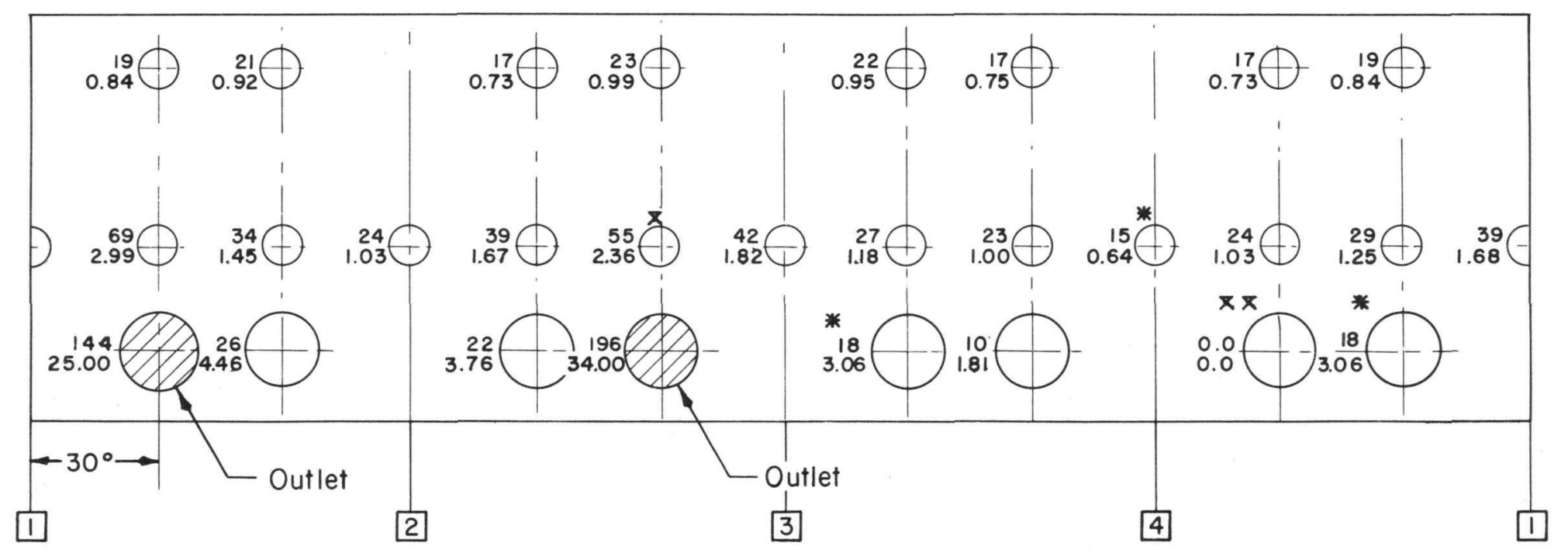

* Estimated values, fps

$x \times$ Verified with smoke

FIGURE 9. DEVELOPMENT OF HOLD-DOWN BARREL NO. I SHOWING AIR VELOCITIES THROUGH HOLES AND FLOW DISTRIBUTION FOR OPERATION WITH TWO ADJACENT LOOPS

Upper numbers show air velocity through each hole, fps.

Lower numbers show percentage of total flow through each hole. 
Figure 10 is a development of the hold-down barrel showing data for operation with two opposed loops. The two holes in line with the two outlets passed 57.5 per cent of the total flow, leaving 42.5 per cent for the other 26 holes.

Comparison of data from Figures $7,8,9$, and 10 shows that the percentage of total flow pasing through each hole was not greatly influenced by the number of loops in operation, except that a large proportion of the total flow passed through each large hole in line with an operating outlet.

\section{Air Circulation in the Upper Plenum \\ With Hold-Down Barrel No. 1}

The general directions of air circulation in the upper plenum were observed using titanium tetrachloride smoke as a tracer. A Lucite window was installed in the top of the dome, and another was installed in the side of the model, opposite a hole in the hold-down barrel, to permit observation of smoke in the plenum. Tests were run with four loops, three loops, two adjacent loops, and two opposed loops. For each test, preliminary data were taken at very low air flows, as patterns were more readily observed. The air flow was then increased to usual model test conditions, and the flow patterns were verified.

Figure 11 shows the air-circulation pattern in the upper plenum with four-loop flow. In general, flow from the core passed outward through the control-rod guides in the bottom half of the plenum and entered the holes in the hold-down barrel. This flow generated secondary flow patterns which circulated coolant throughout the upper plenum. Secondary flow patterns were well defined and readily traced throughout the upper plenum, and resulted in considerable mixing. The flow from the core outlets to the hold-down-barrel inlets entrained surrounding air, causing downward flow at the model center line and upward circulation at the inside surfaces of the hold-down barrel and pressure vessel. Some asymmetry of flow was observed in all tests, with flow in one direction over much of the dome surface. Entrainment of air around the periphery of the core resulted in downward flow along the outside of the plenum space, below the outlets.

Between the zones of upward flow at the outer surfaces and downward flow at the center line there was an annular region in which smaller vortices we re constantly formed and dissipated. These were 2 to $4 \mathrm{in}$. in diameter, and filled the space between upward and downward streams.

Figure 12 shows air circulation in the upper plenum with three-loop flow. The general features of the flow pattern were similar to those in Figure 11, except that the asymmetrical outlet conditions changed the recirculation patterns somewhat. Since about 63.5 per cent of the total flow entered the three holes in line with the model outlets, momentum transfer to recirculating fluid at the se locations was high, resulting in upward flow along the pressure vessel. Downward flow occurred in the region above the closed outlet. The usual downward flow at the center line was also observed. 


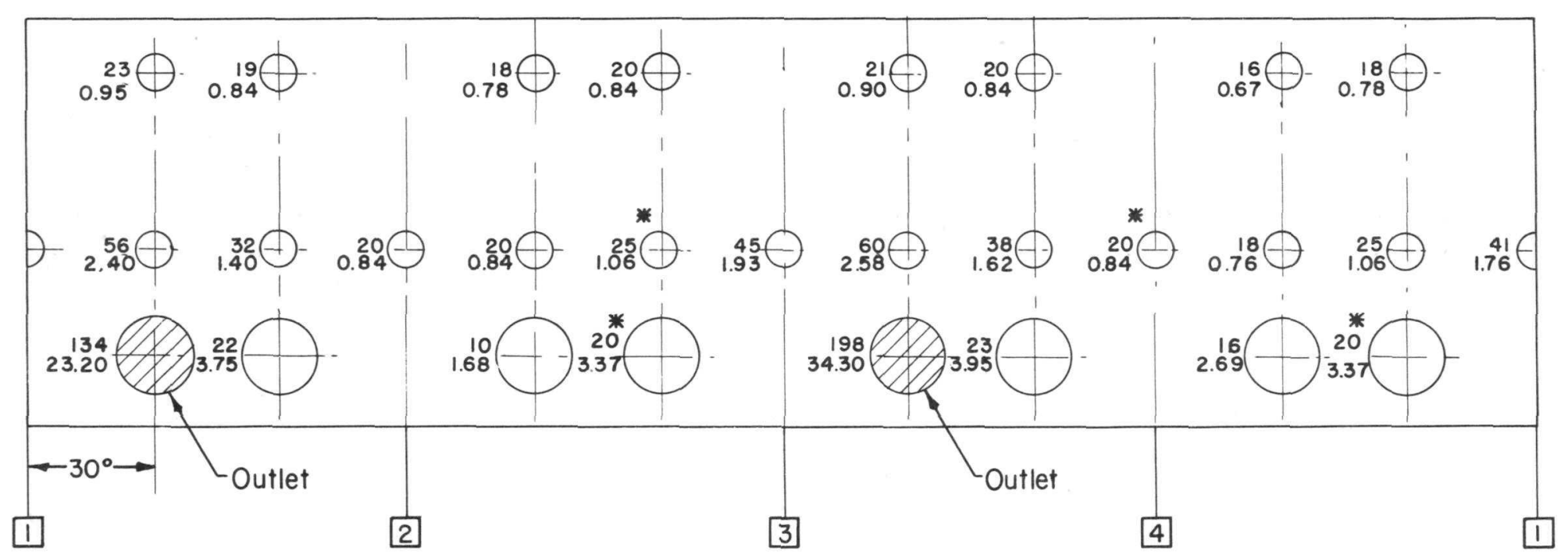

* Estimated values, fps

FIGURE 10. DEVELOPMENT OF HOLD-DOWN BARREL NO. 1 SHOWING AIR VELOCITIES THROUGH HOLES AND FLOW DISTRIBUTION FOR OPERATION WITH TWO OPPOSED LOOPS

Upper numbers show air velocity through each hole, fps.

Lower numbers show percentage of total flow through each hole. 


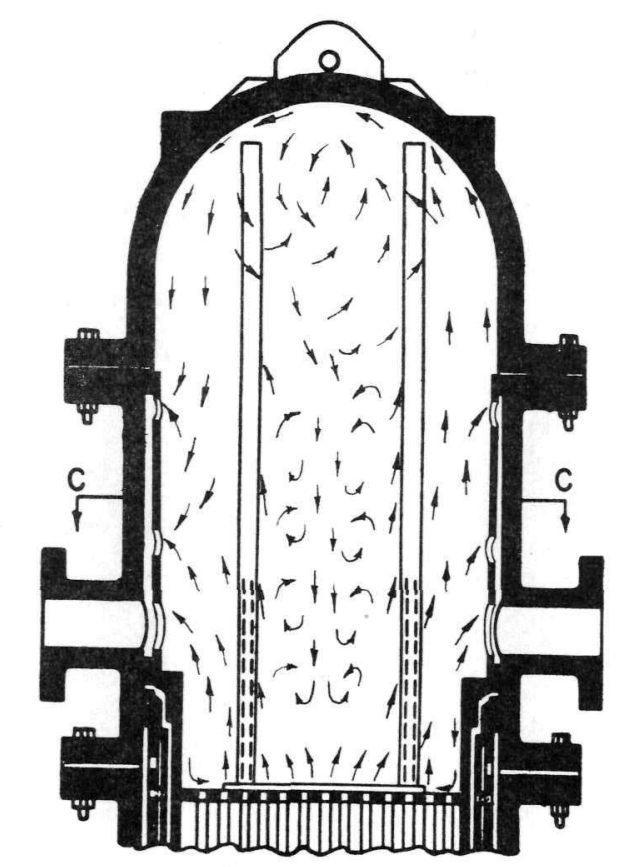

Section AA

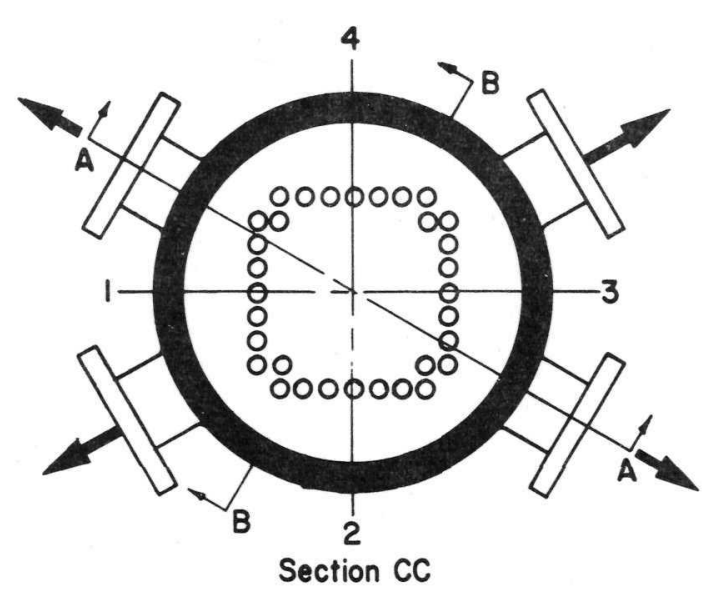

Section CC

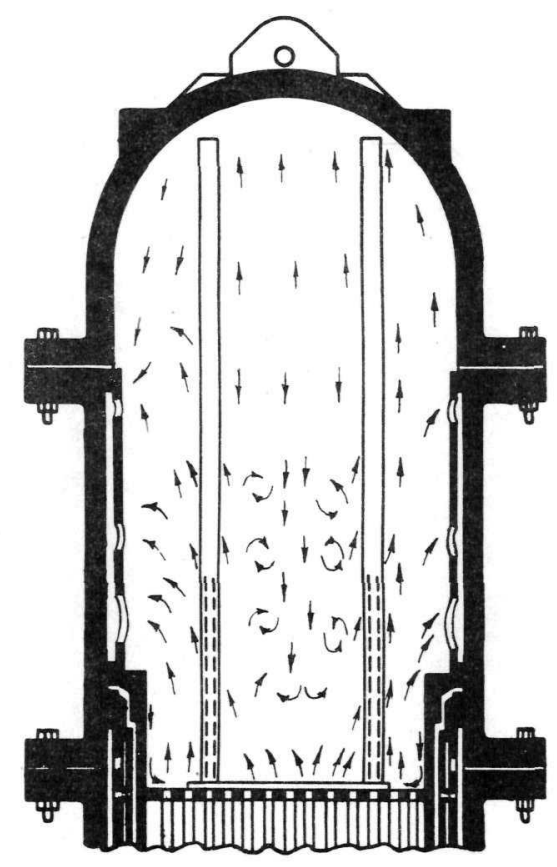

Section BB

FIGURE 11. AIR CIRCULATION IN THE UPPER PLENUM OF THE QUARTER-SCALE FLOW MODEL WITH HOLD-DOWN BARREL NO. 1 WITH FOUR LOOPS OPERATING 


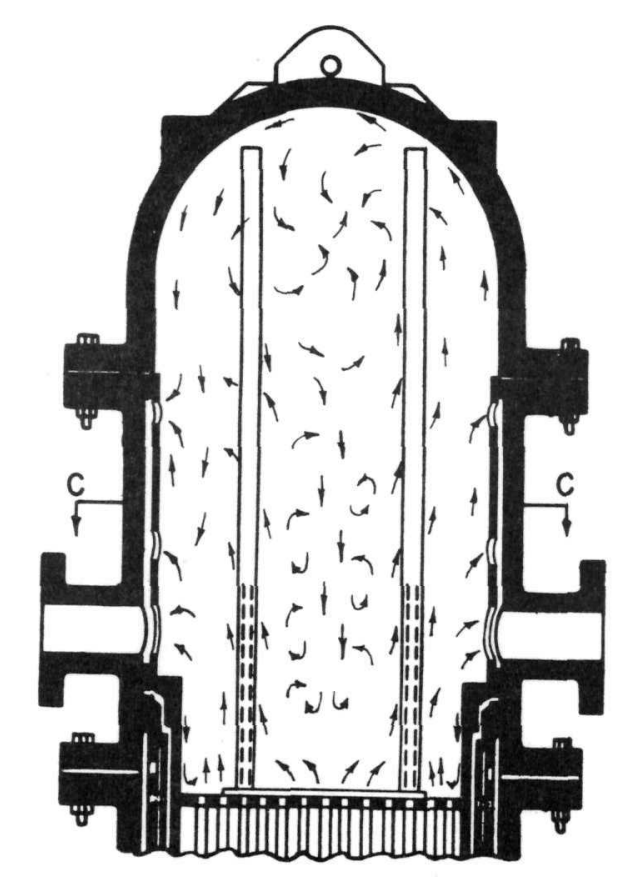

Section AA

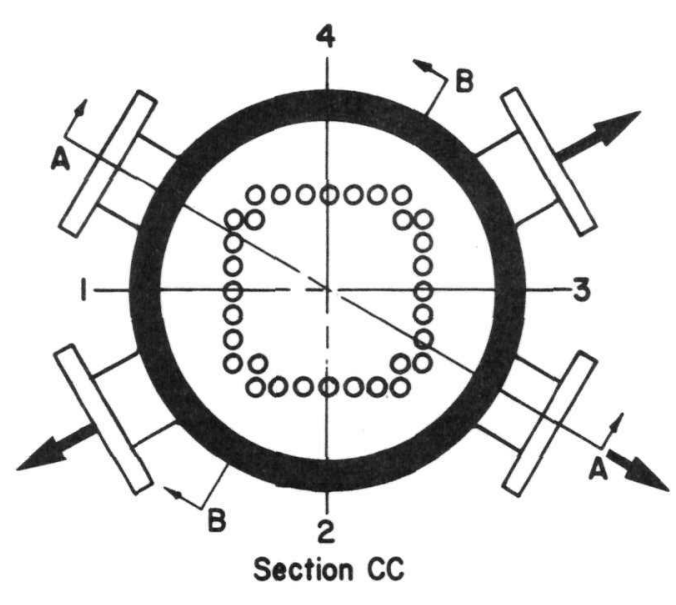

FIGURE 12. AIR CIRCULATION IN THE UPPER PLENUM OF THE QUARTER-SCALE FLOW MODEL WITH HOLD-DOWN BARREL NO. 1 WITH THREE LOOPS OPERATING 
Figure 13 shows air circulation with two adjacent loops in operation. The recirculation pattern was again established by momentum transfer from the primary-fluid stream and reflected the asymmetric flow conditions.

Figure 14 shows air circulation with two opposed loops in operation. Of the two views, Section BB represents more closely the flow through the section of the outlets, and Section AA represents the flow between the outlets.

With each of the four operating conditions, extensive recirculation and turbulence were observed and no stagnant regions were found.

$\frac{\text { Velocities and Directions of Flow at the Inner Surface }}{\text { of the Upper Dome With Hold-Down Barrel No. } 1}$

To determine flow velocities over the inner surface of the upper dome, a number of 1/4-in. holes were drilled through the dome, and velocities and directions of flow were determined at each of these locations with a two-hole cylindrical yaw probe. An inclined manometer with a sensitivity of $0.001 \mathrm{in}$. of water was used to measure yawprobe pressures, making it possible to measure flow velocities as low as $2 \mathrm{fps}$.

Figure 15 shows velocities and directions of flow at the inner surface of the upper dome for four-loop flow. Velocities ranged from 5.6 to $18.4 \mathrm{fps}$, and were all in the same general direction. Positions of outlets are indicated by arrows.

Figure 16 shows velocities and directions of flow at the inner surface of the upper dome for three-loop operation. Velocities ranged from 4.5 to $11.5 \mathrm{fps}$, as the flow was lower than that for Figure 15. At one point the velocity was below the limit of sensitivity of the yaw probe. A check with smoke showed positive flow at this location.

Figure 17 shows velocities and directions of flow at the inner surface of the upper dome for operation with two adjacent loops. Velocities ranging from 2.3 to $11.6 \mathrm{fps}$ were measured. Flow was generally in the same direction except for the large eddy shown at the right side of the figure. When the test was repeated with two different outlets 180 deg from those used for the above test, a similar flow pattern, rotated 180 deg, was obtained.

Figure 18 shows velocities and directions of flow at the inner surface of the upper dome with two opposed loops in operation. The highest velocity measured for this test was $6.2 \mathrm{fps}$, and there were eight points at which velocities were below $1.6 \mathrm{fps}$. A check with titanium tetrachloride smoke showed positive air flow at all points where velocity was too low to measure. 


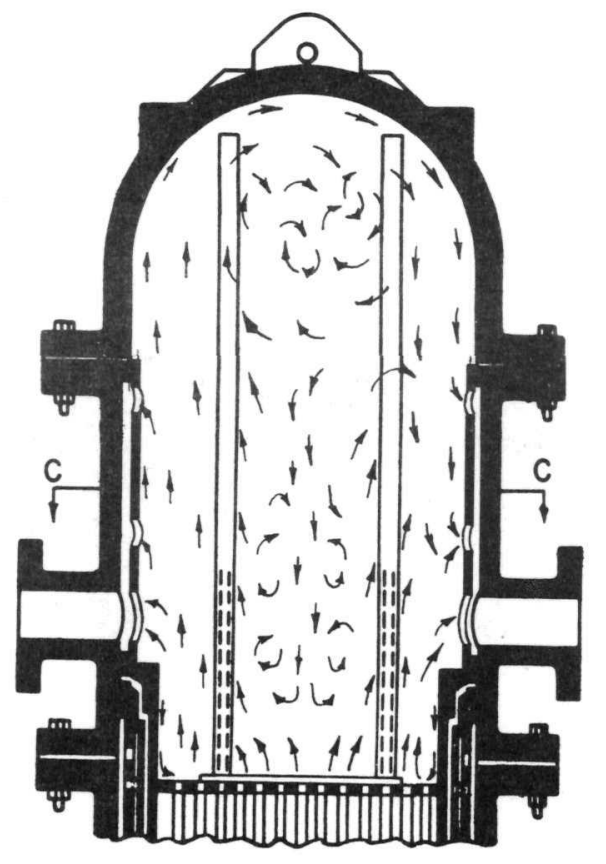

Section AA
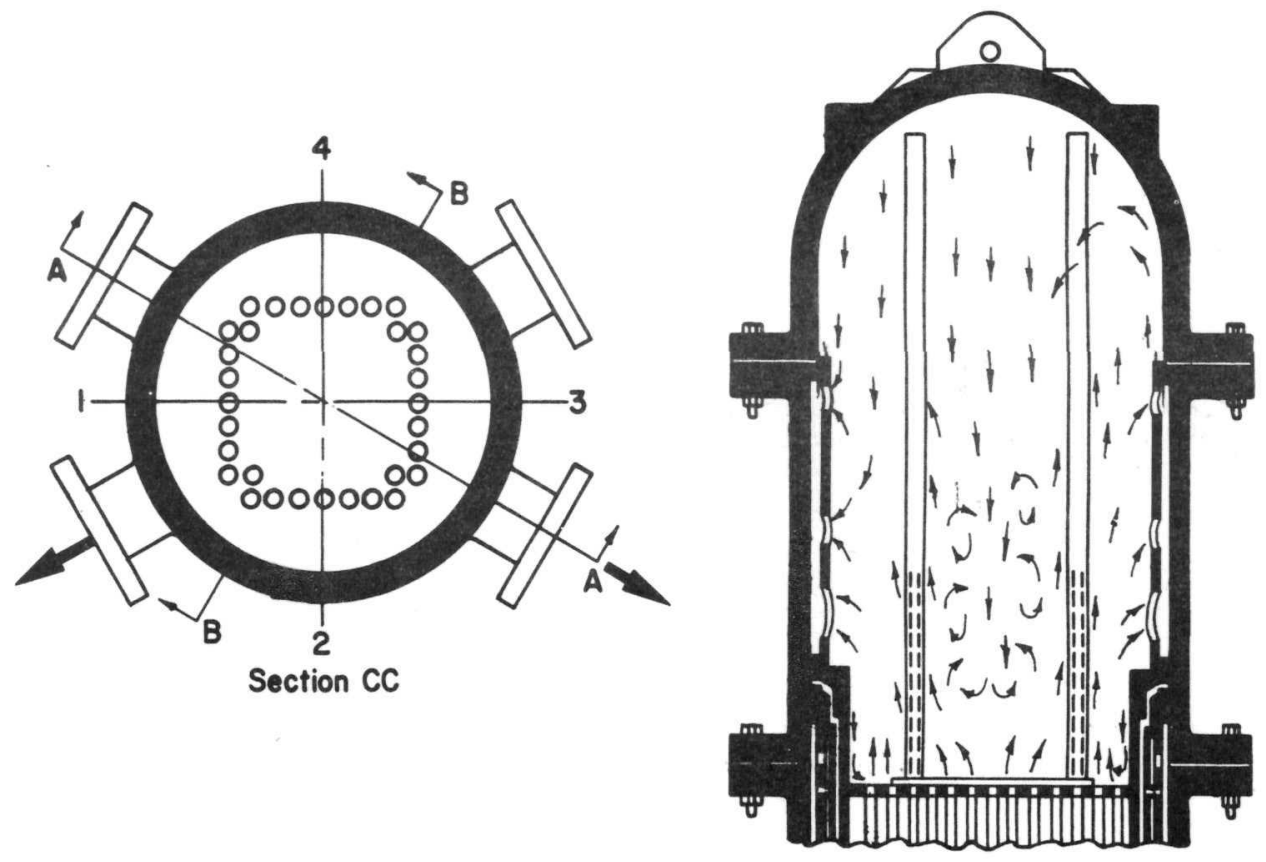

Section BB

FIGURE 13. AIR CIRCULATION IN THE UPPER PLENUM OF THE QUARTER-SCALE FLOW MODEL WITH HOLD-DOWN BARREL NO. 1 WITH TWO ADJACENT LOOPS OPERATING 


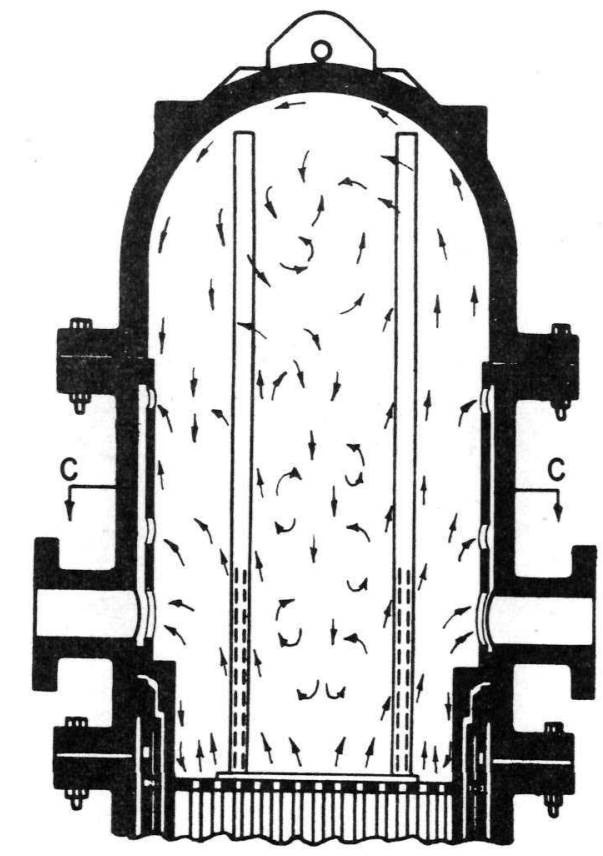

Section AA

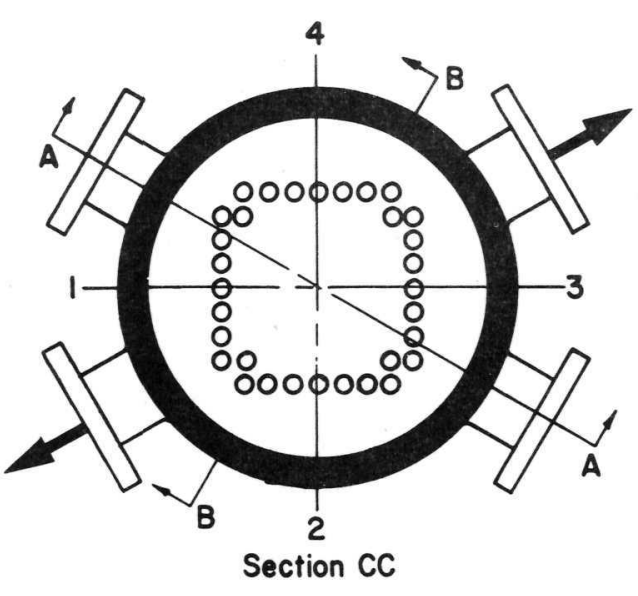

Section CC

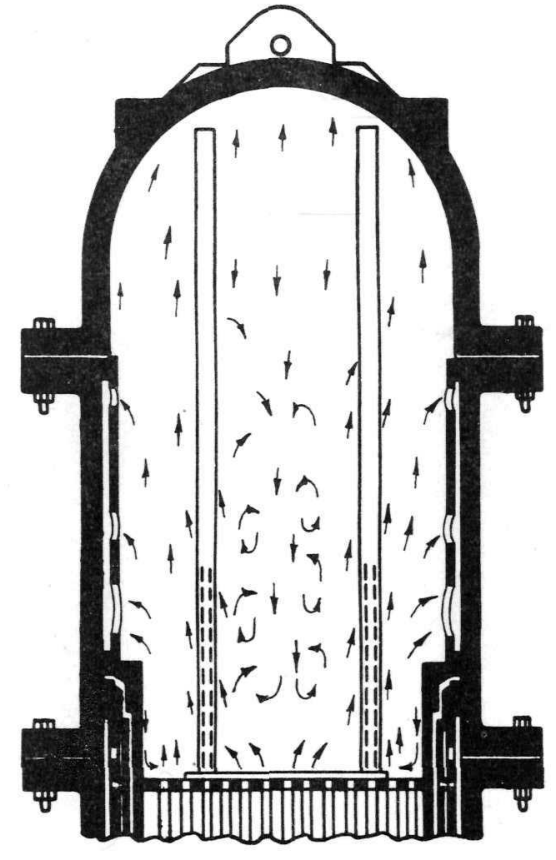

Section BB

FIGURE 14. AIR CIRCULATION IN THE UPPER PLENUM OF THE QUARTER-SCALE FLOW MODEL WITH HOLD-DOWN BARREL NO. I WITH TWO OPPOSED LOOPS OPERATING 


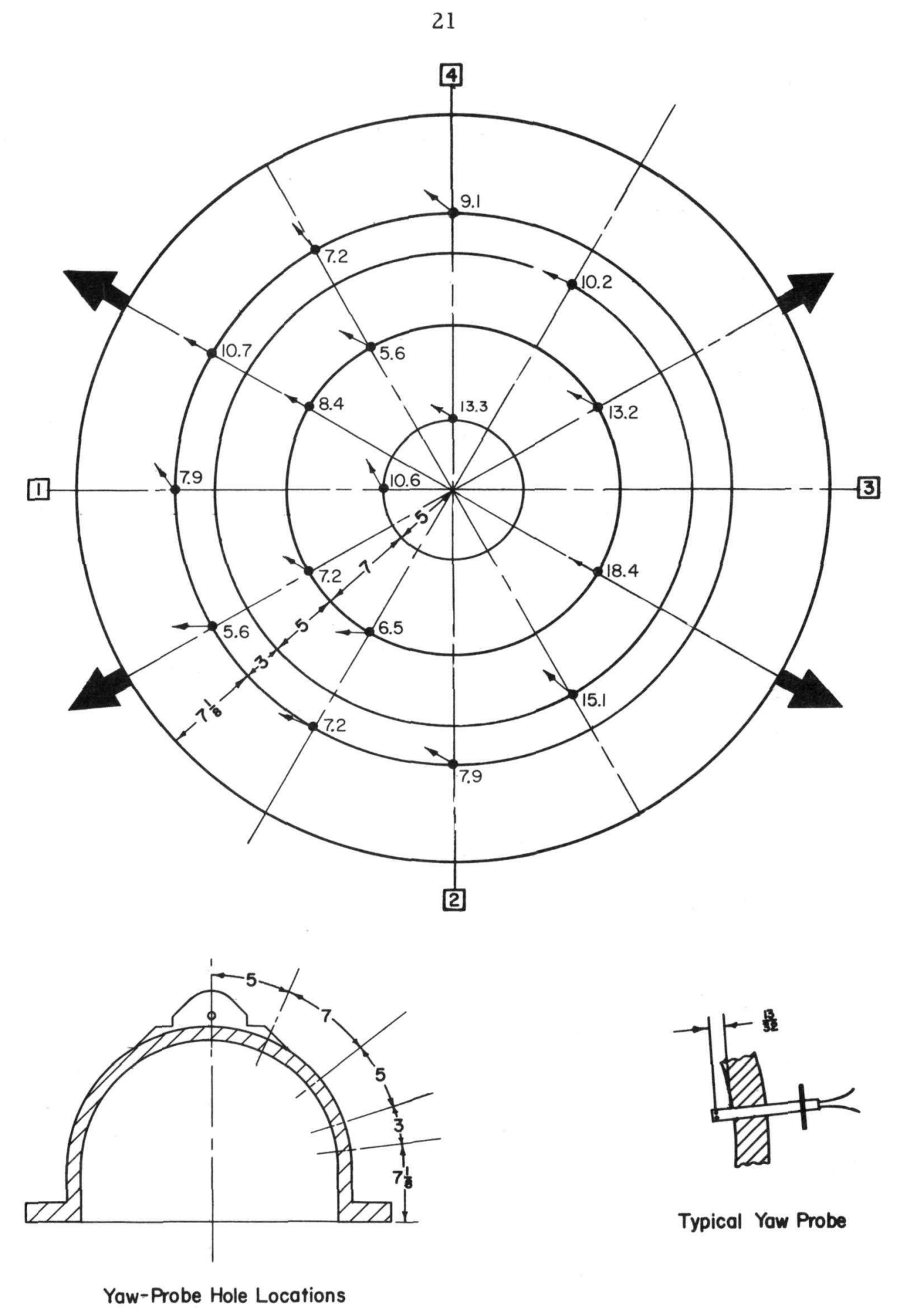

FIGURE 15. VELOCITIES AND DIRECTIONS OF AIR FLOW AT THE INNER SURFACE OF THE UPPER DOME WITH HOLD-DOWN BARREL NO. 1 FOR FOUR-LOOP OPERATION

Arrows indicate flow direction, and numbers indicate velocity. 


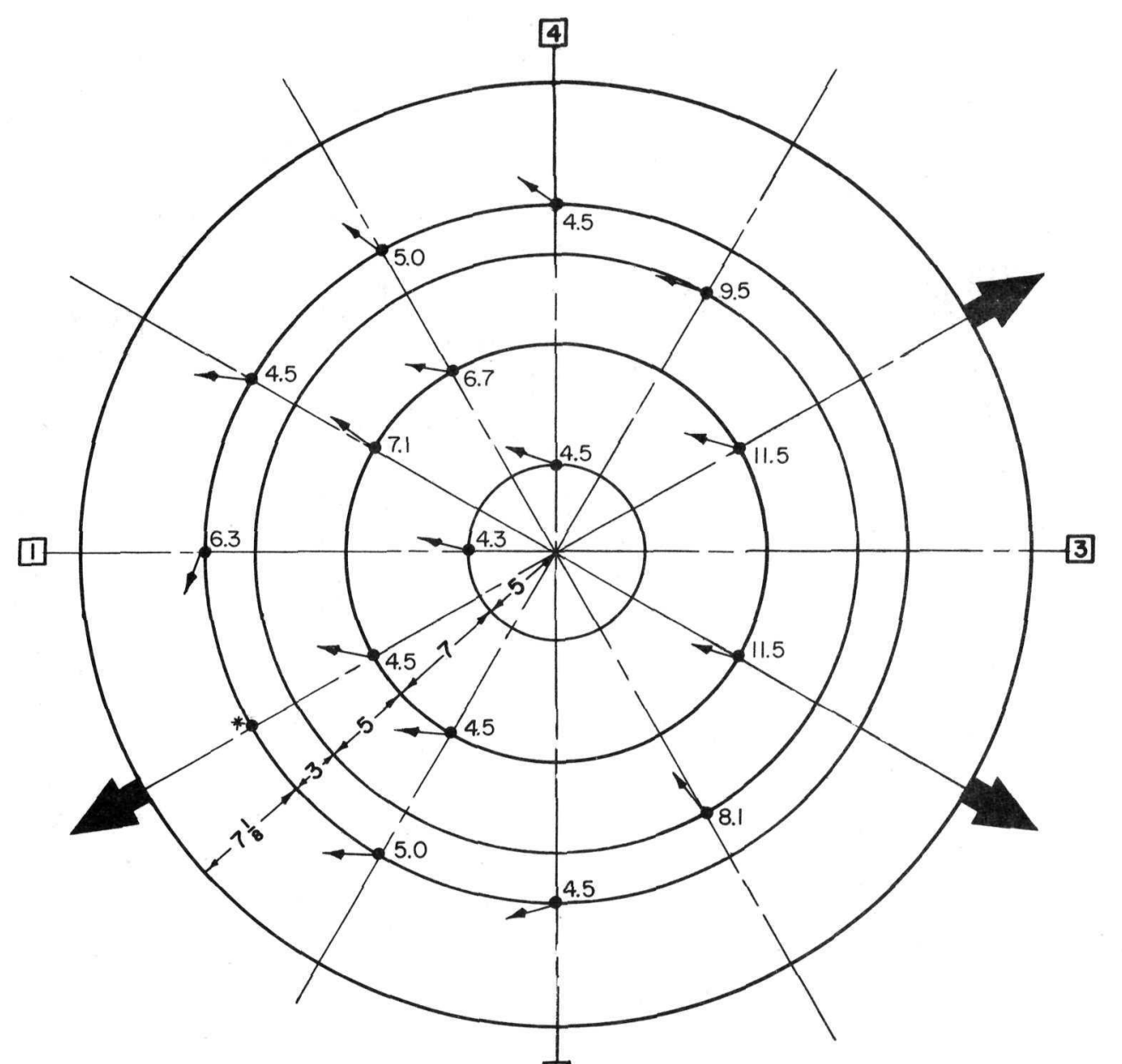

* Velocity below $2 \mathrm{fps}$

自
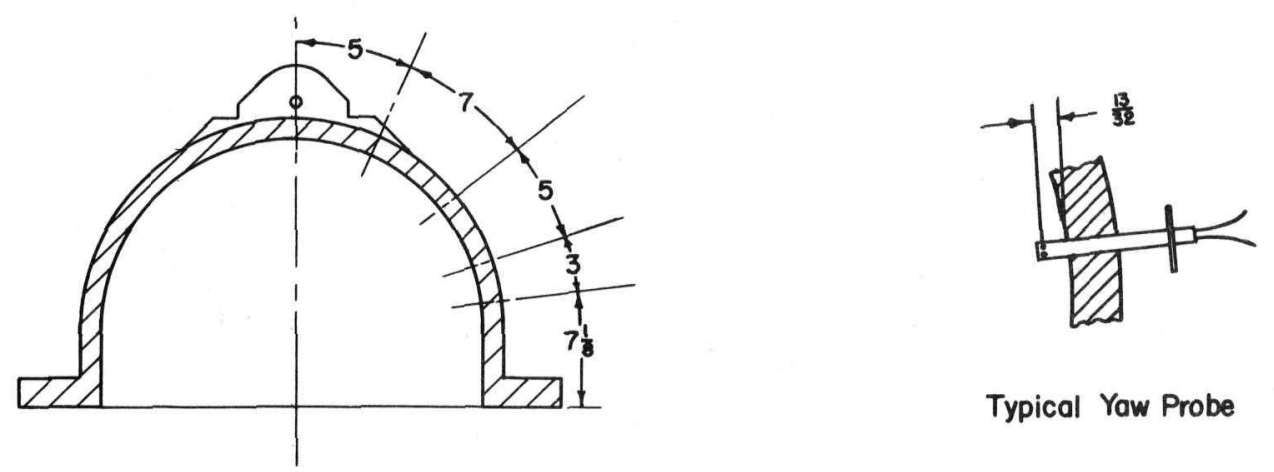

Typical Yaw Probe

Yaw-Probe Hole Locations

FIGURE 16. VELOCITIES AND DIRECTIONS OF FLOW AT THE INNER SURFACE OF THE UPPER DOME WITH HOLD-DOWN BARREL NO. I FOR THREE-LOOP OPERATION

Arrows indicate flow direction, and numbers indicate velocity. 

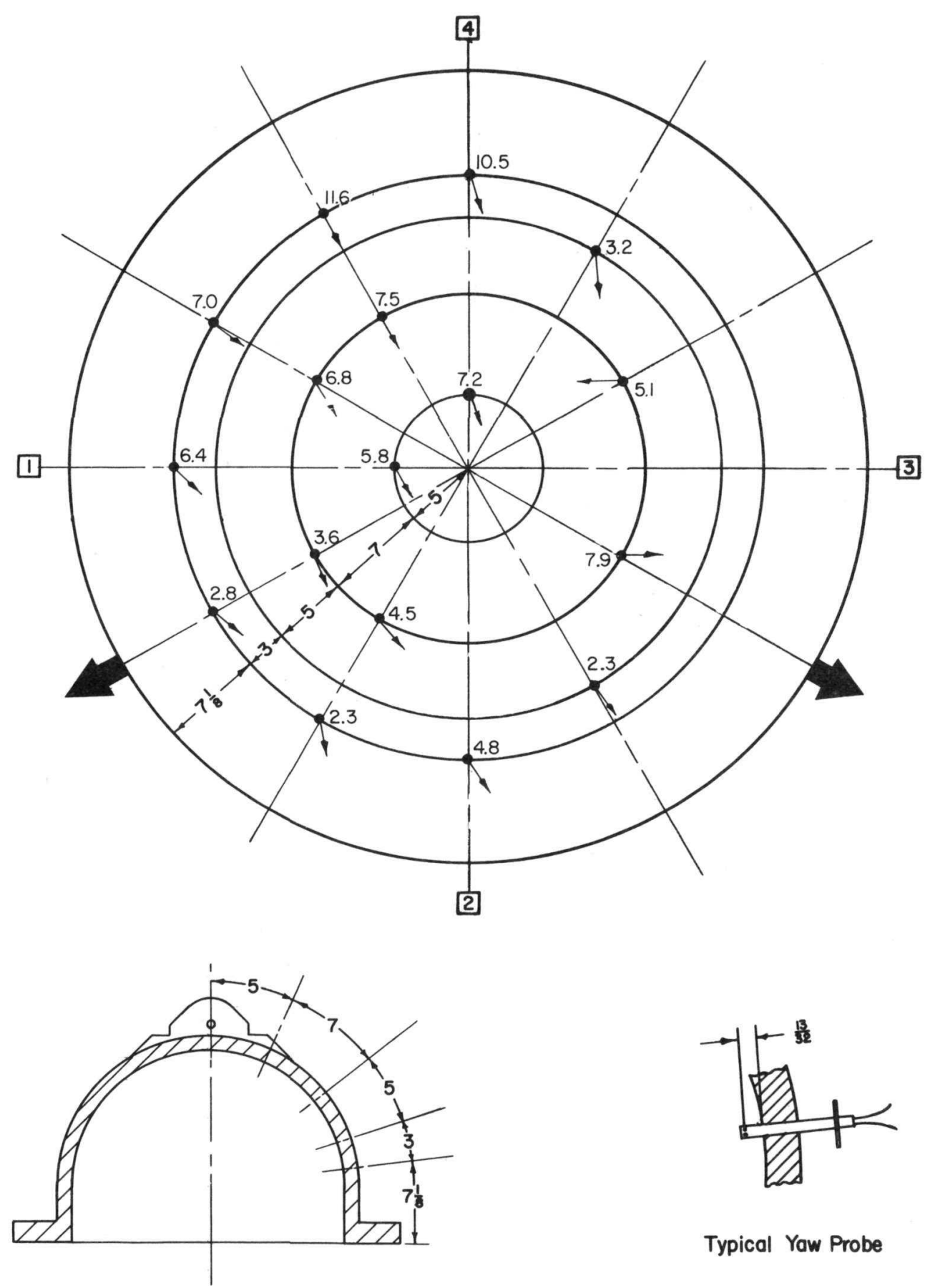

Typical Yaw Probe

Yaw-Probe Hole Locations

FIGURE 17. VELOCITIES AND DIREC TIONS OF AIR FLOW AT THE INNER SURFACE OF THE UPPER DOME WITH HOLD-DOWN BARREL NO. 1 FOR OPERATION WITH TWO ADJACENT LOOPS

Arrows indicate flow direction, and numbers indicate velocity. 

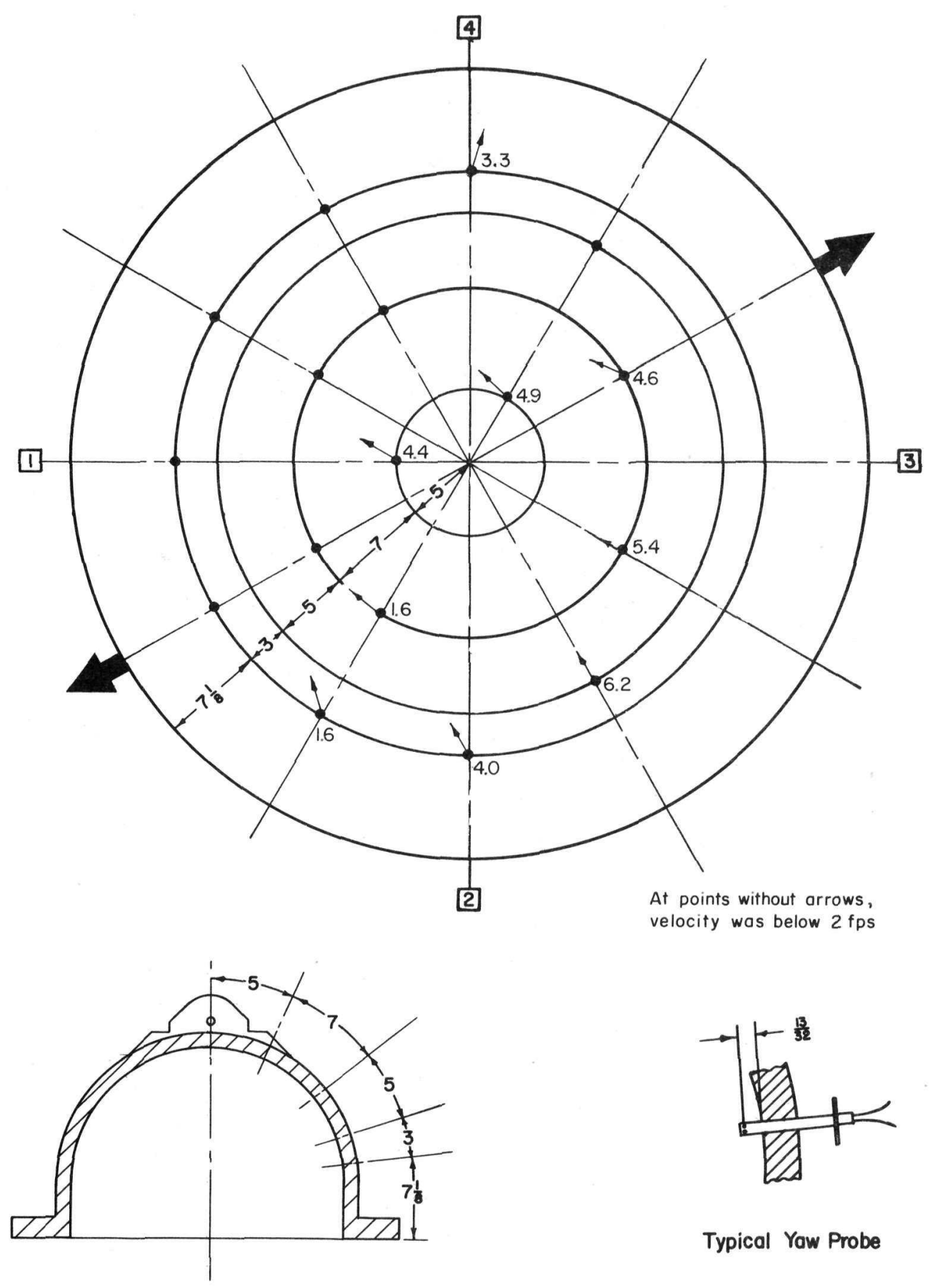

Typical Yaw Probe

Yaw-Probe Hole Locations

FIGURE 18. VELOCITIES AND DIRECTIONS OF FLOW AT THE INNER SURFACE OF THE UPPER DOME WITH HOLD-DOWN BARREL NO. 1 FOR OPERATION WITH TWO OPPOSED LOOPS

Arrows indicate flow direction, and numbers indicate velocity. 


\title{
STUDIES OF FLOW IN THE UPPER PLENUM OF THE QUARTER- SCALE MODEL WITH HOLD-DOWN BARREL NO. 2
}

\author{
Description of Hold-Down Barrel No. 2
}

Hold-Down Barrel No. 2, which was installed following tests with Hold-Down Barrel No. 1, was designed to admit 95 per cent of the coolant through an annular slot at the top of the hold-down barrel, and 5 per cent through a ring of 24 holes near the bottom. This resulted in flow patterns in the upper plenum which were quite different from those with Hold-Down Barrel No. 1.

Figure 19 is a photograph of Hold-Down Barrel No. 2. The barrel was designed by the Bettis Laboratory of the Atomic Energy Commission, and was constructed of plastic reinforced with glass fiber, by the Magic Circle Tool and Engineering Company of Lees Summit, Missouri.

Figure 20 is a photograph of the upper plenum of the quarter-scale model with Hold-Down Barrel No. 2 installed.

The test procedures used with Hold-Down Barrel No. 2 were similar to those with Hold-Down Barrel No. 1. Tests were run to determine circulation patterns in the upper plenum, velocities over the inner surface of the upper dome, velocities between the hold-down barrel and the pressure vessel and a flow coefficient applicable to flow into the hold-down-barrel openings. Data were obtained for operation with four loops, three loops, two adjacent loops, and two opposed loops.

\section{Air Circulation in the Upper Plenum of the Quarter-Scale Model With Hold-Down Barrel No. 2}

Figure 21 shows air-circulation patterns in the upper plenum of the quarter-scale model for operation with four loops. The air stream from the core flows directly to the annular slot at the top of the hold-down barrel, setting up recirculation throughout the plenum. Air entrained around the outside of the core, at the bottom of the plenum, passes downward over the lower part of the hold-down barrel. Entrainment also causes downward flow at the center of the plenum, and upward flow over entire periphery of the upper dome. It appears that flow into the annular slot was symmetrical, so that flow throughout the upper plenum was nearly symmetrical. The flow pattern observed with Hold-Down Barrel No. 2 was rather different from the pattern observed with Hold-Down Barrel No. 1.

Figure 22 shows flow patterns in the upper plenum for operation with three loops. The flow pattern was similar to that for four loops, but was somewhat less symmetrical, as indicated by velocities measured at the dome surface.

Figure 23 shows flow patterns in the upper plenum for operation with two adjacent loops. For this configuration, the flow pattern was similar to that with four loops, with some asymmetry of flow over the upper dome. 


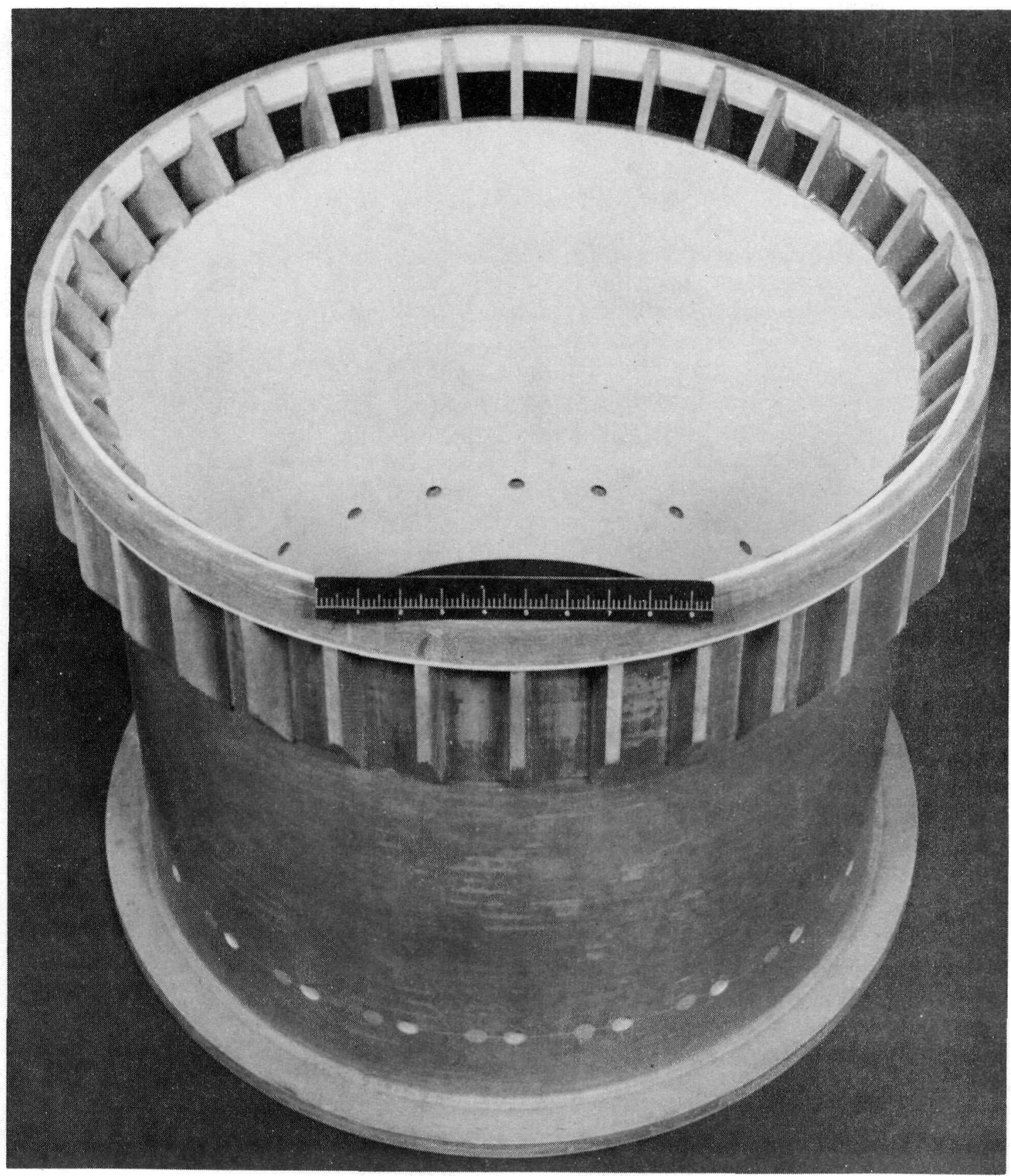

N35917

FIGURE 19. PHOTOGRAPH OF HOLD-DOWN BARREL NO. 2 FOR THE QUARTER-SCALE FLOW MODEL 


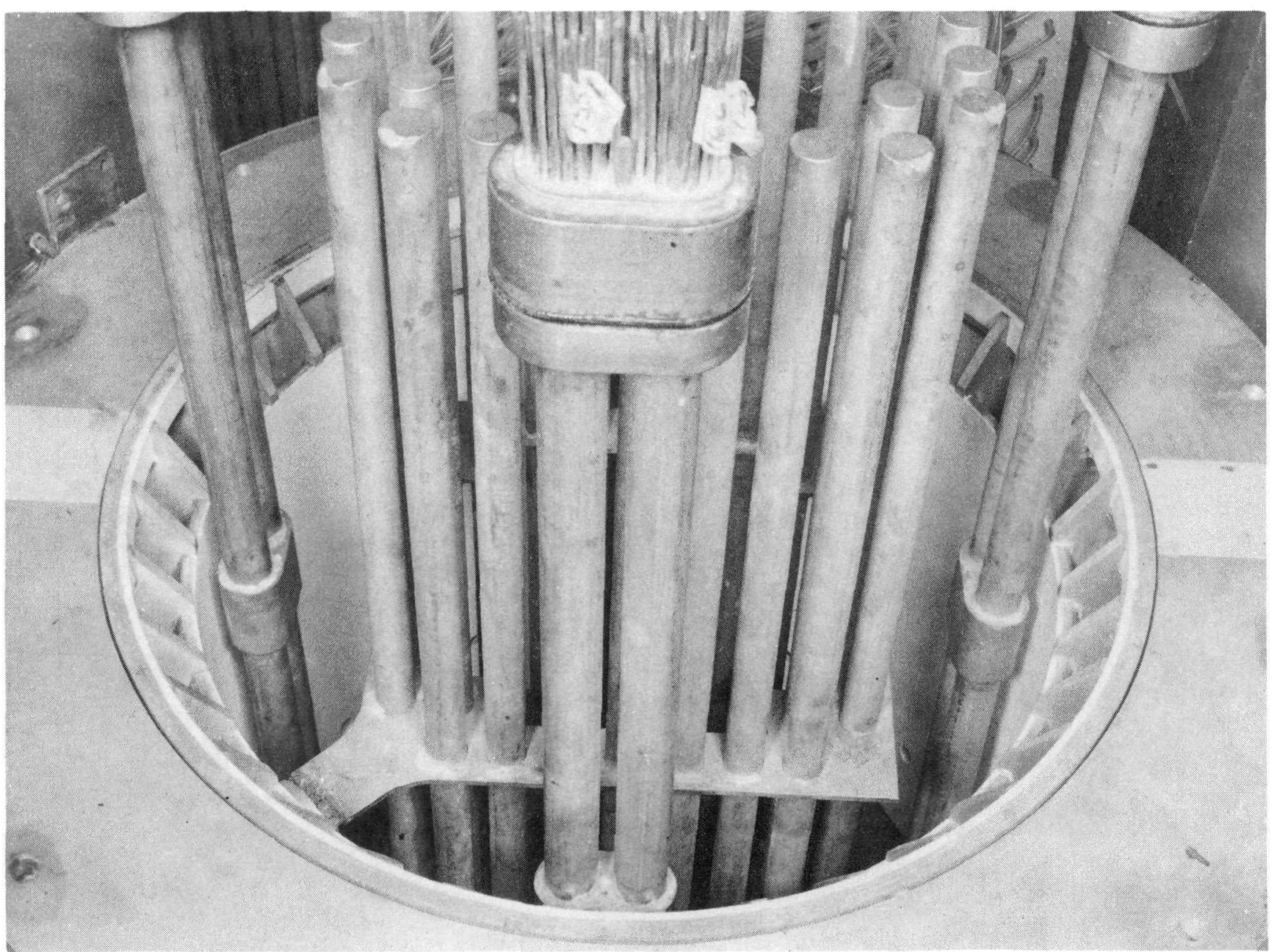

N36116

FIGURE 20. PHOTOGRAPH OF HOLD-DOWN BARREL NO. 2 INSTALLED IN THE UPPER PLENUM OF THE QUARTER-SCALE FLOW MODEL 


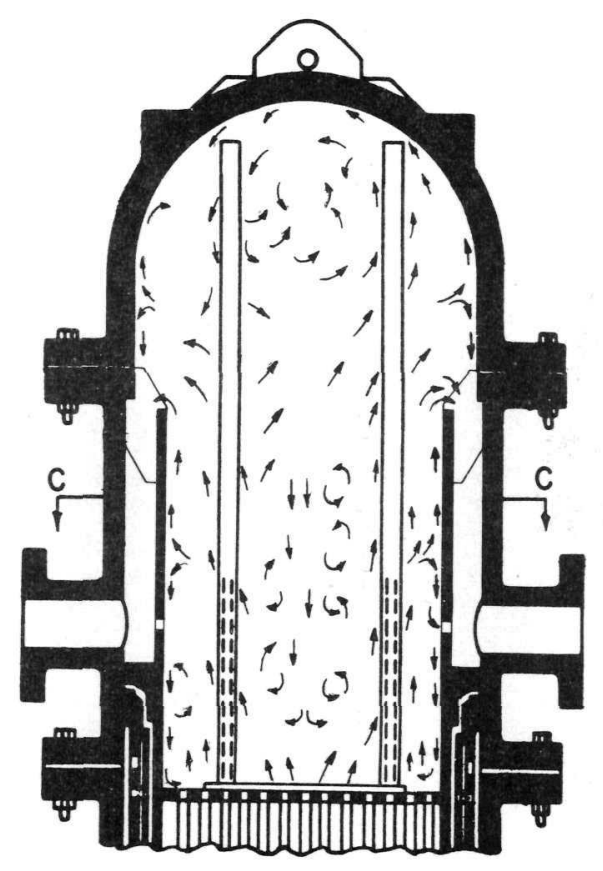

Section AA

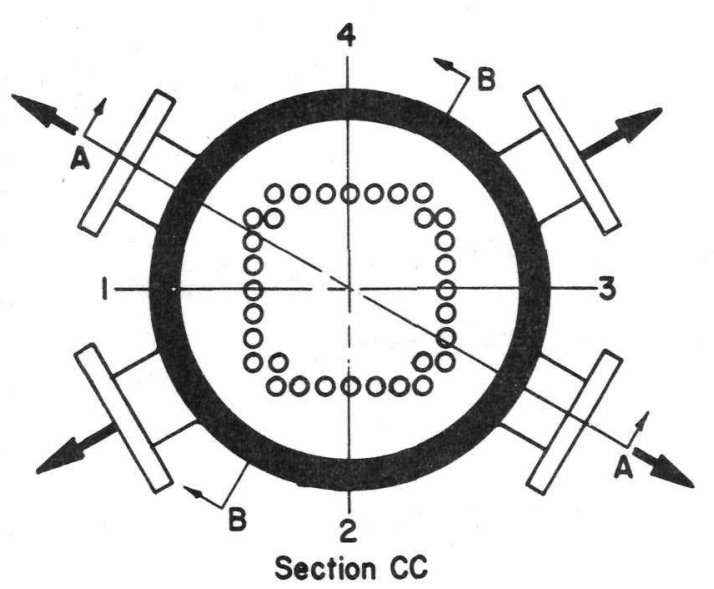

Section $c c$

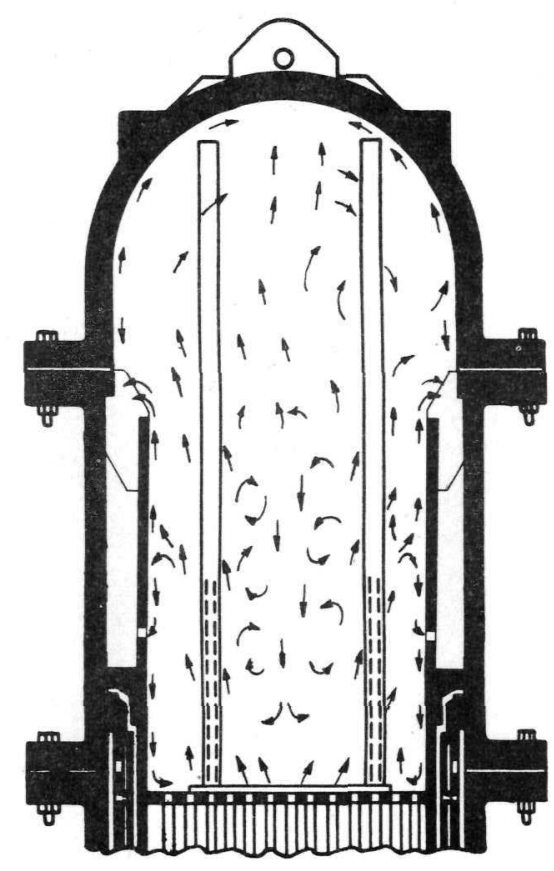

Section BB

FIGURE 21. FLOW PATTERN IN UPPER PLENUM WITH HOLD-DOWN BARREL NO. 2 FOR OPERATION WITH FOUR LOOPS 


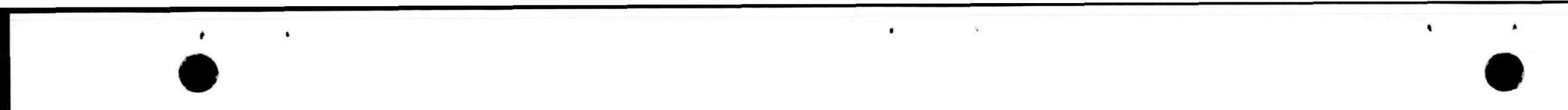

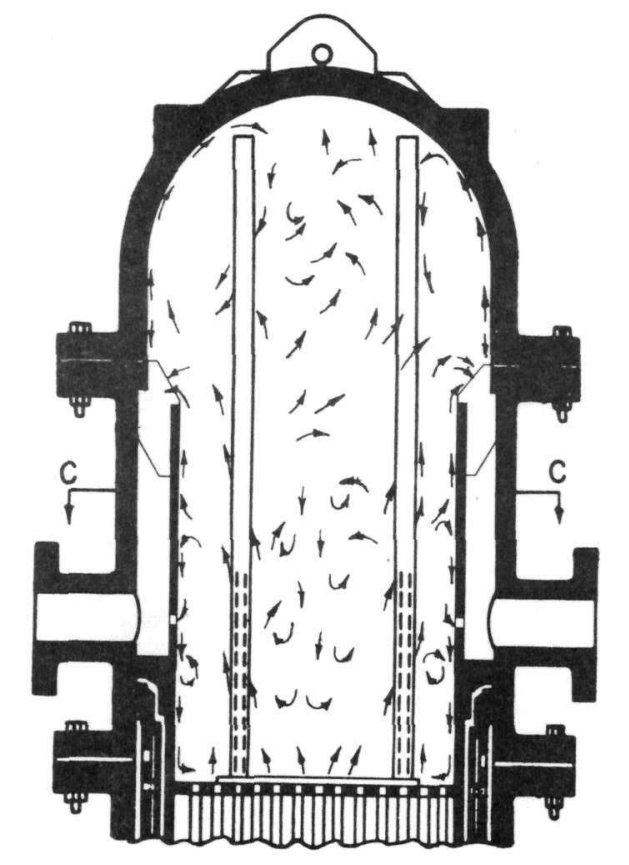

Section AA
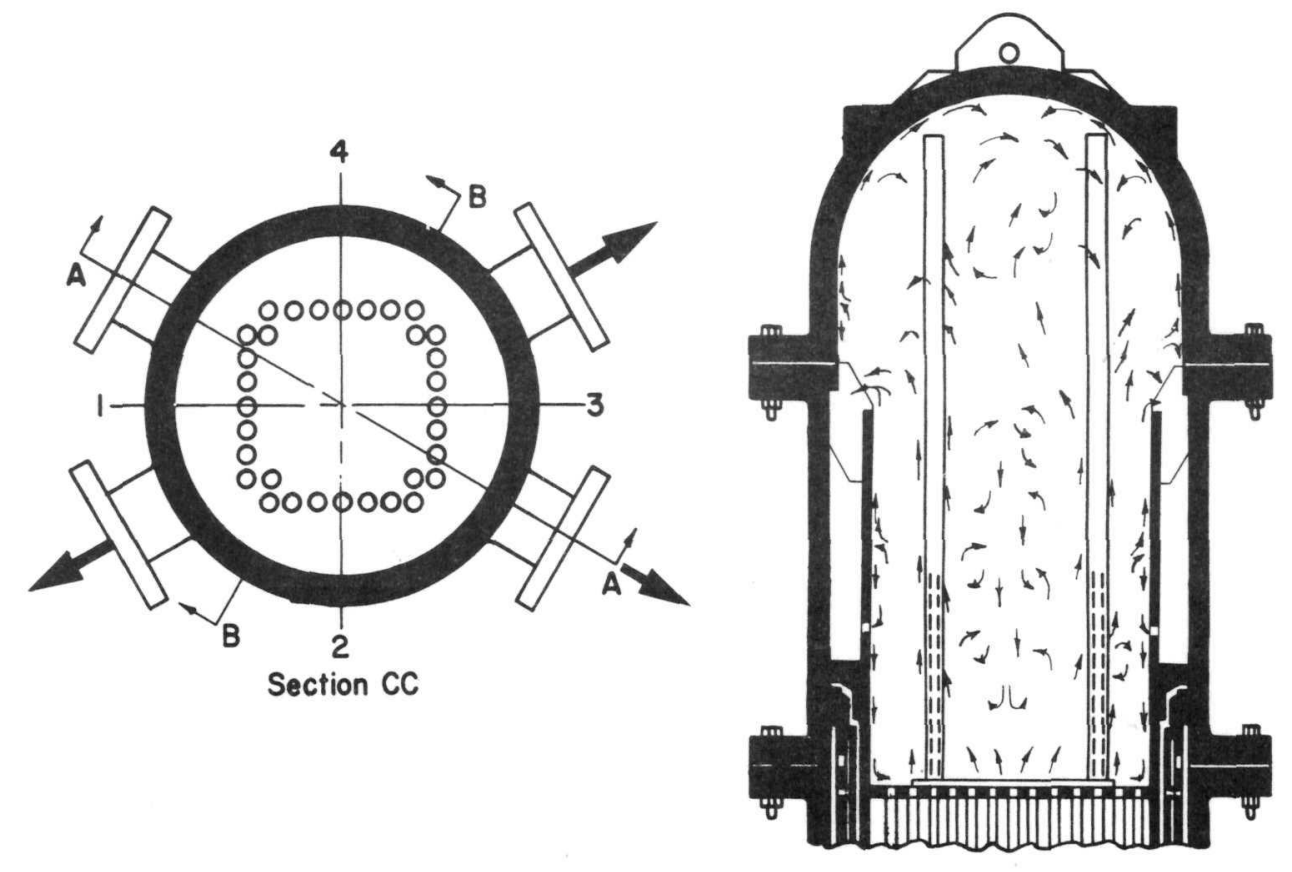

Section BB

FIGURE 22. FLOW PATTERN IN THE UPPER PLENUM WITH HOLD-DOWN BARREL NO. 2 FOR OPERATION WITH THREE LOOPS 


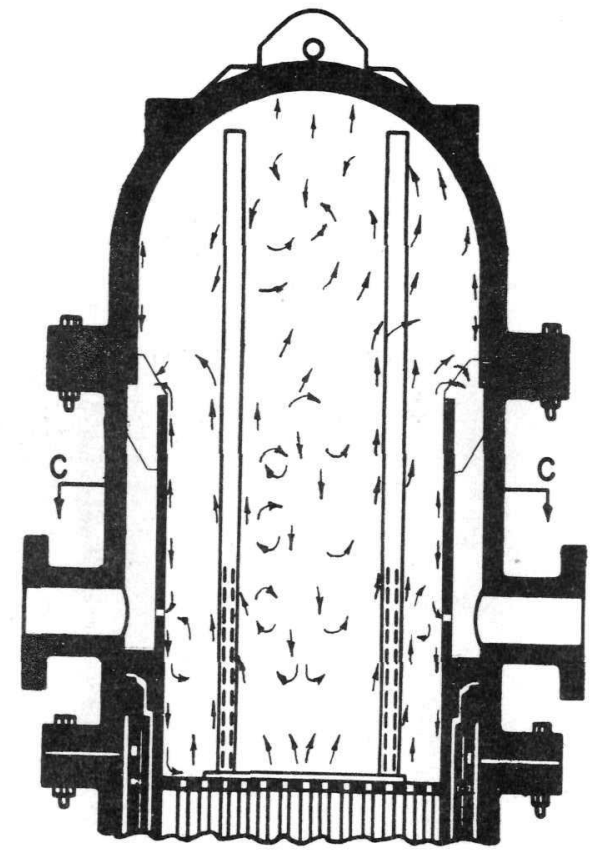

Section AA

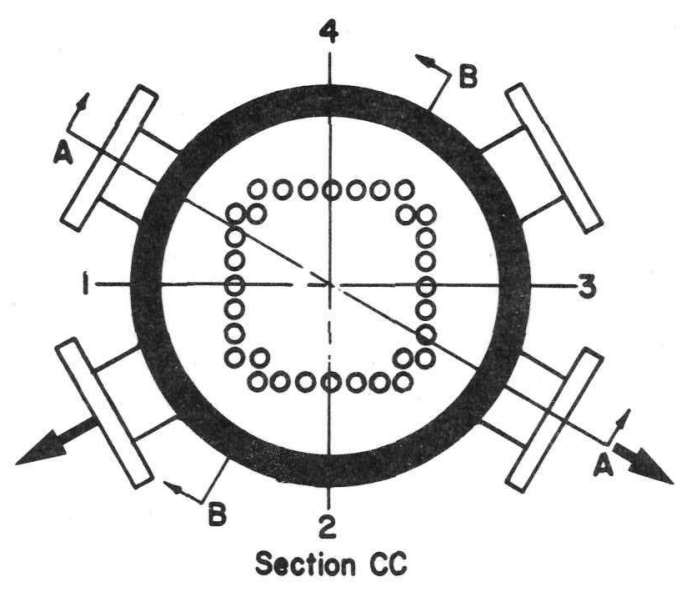

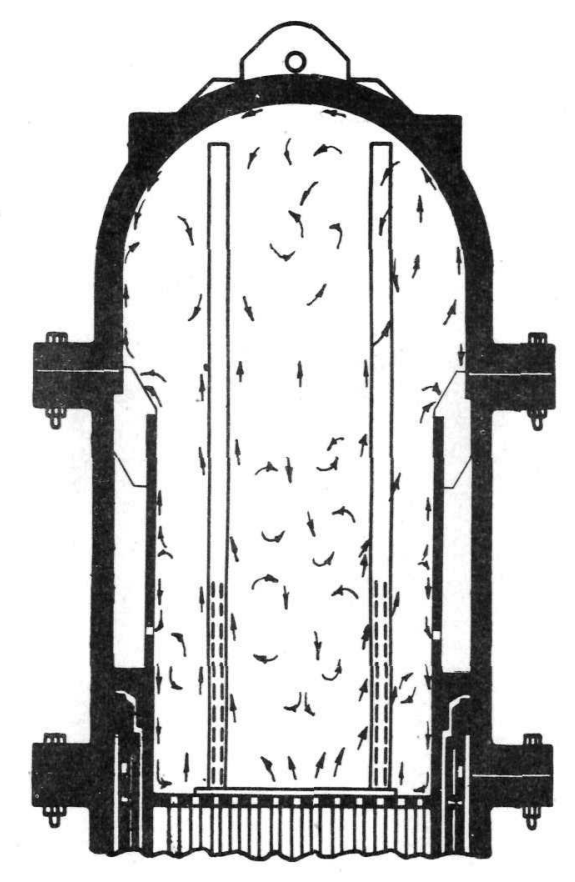

Section BB 
Figure 24 shows flow patterns in the upper plenum with two opposed loops in operation. This was the least symmetrical flow pattern observed with Hold-Down Barrel No. 2, with downward flow over a small part of the upper dome. The flow pattern was, in other respects, similar to that for four-loop flow.

\title{
Velocities and Directions of Flow at the Inner Surface of the Upper Dome With Hold-Down Barrel No. 2
}

Velocities and directions of flow were measured at a number of points at the inner surface of the upper dome using a yaw probe. In general, it appeared that air flowed upward along the surface of the dome, converging into areas at which it flowed downward into the plenum. These areas of convergence varied in number and position with the number of outlets in use. The entire inner surface of the dome was swept by moving air under all operating conditions.

Figure 25 shows velocities and directions of flow at the inner surface of the upper dome of the model with Hold-Down Barrel No. 2, for operation with four loops. Measured velocities ranged from 8.4 to $30.0 \mathrm{fps}$. At one point the direction of flow fluctuated greatly, and is not indicated on the figure, but velocity was high.

Figure 26 shows velocities and directions of flow for operation with three loops. Velocities vary greatly, ranging from 5.0 to $24.0 \mathrm{fps}$.

Figure 27 shows velocities and directions of flow for operation with two adjacent loops. Velocities ranged from 3.7 to $17.1 \mathrm{fps}$.

Figure 28 shows velocities and directions of flow for operation with two opposed loops. Velocities ranged from 3.1 to 17.9 fps.

\author{
Velocities and Directions of Flow in the Space Between \\ Hold-Down Barrel No. 2 and the Pressure Vessel \\ of the Quarter-Scale Model
}

About 95 per cent of the air flowing in the model passes through an annular slot at the top of Hold-Down Barrel No. 2, then passes downward through the space between the hold-down barrel and the pressure vessel to the outlets. The remaining flow passes through 24 small holes at the level of the outlets. The annular exit from the upper plenum has sufficient flow resistance that flow enters around the entire circumference regardless of the number of loops used, but the flow pattern in the passage changes as the number of operating loops is changed. The flow patterns in this space were investigated using yaw probes to measure velocities and directions of air flow while operating with four loops, three loops, two adjacent loops, and two opposed loops. Excellent circulation of air over all parts of the pressure vessel was found under all operating conditions . 


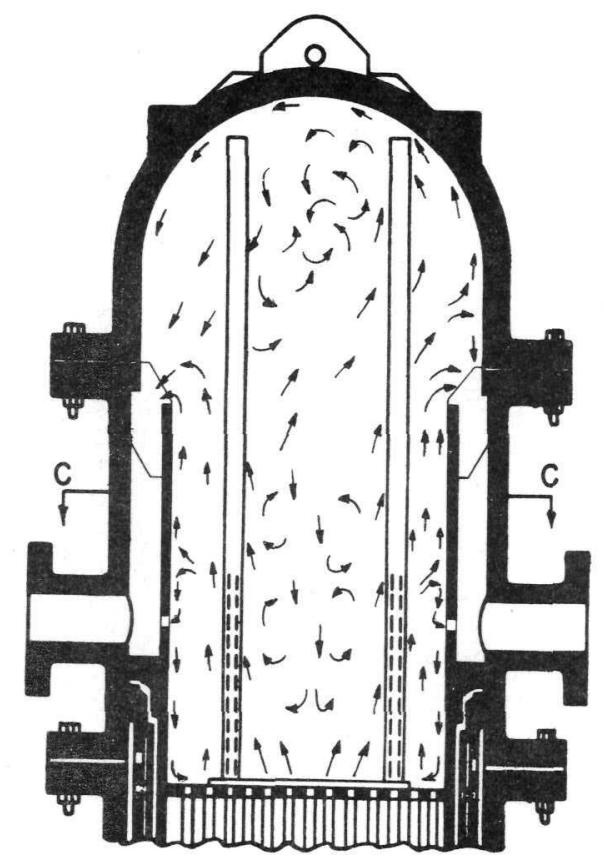

Section AA

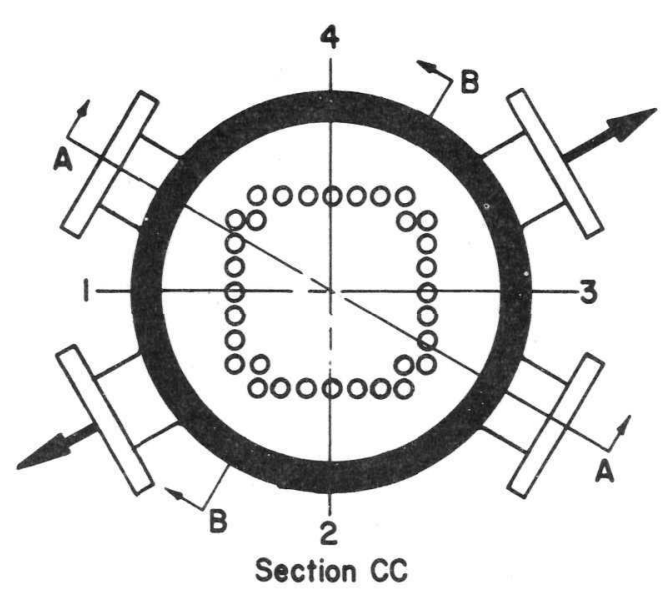

Section CC

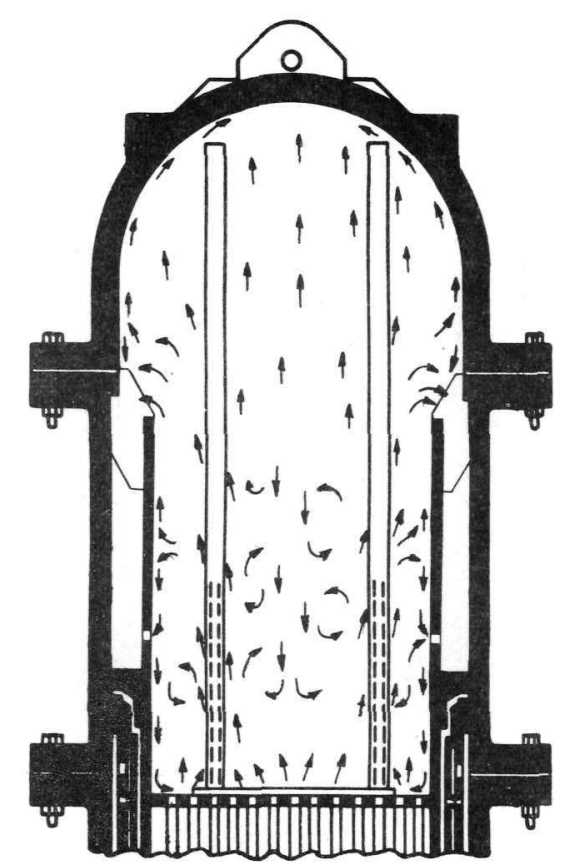

Section BB

FIGURE 24. FLOW PATTERN IN THE UPPER PLENUM WITH HOLD-DOWN BARREL NO. 2 FOR OPERATION WITH TWO OPPOSED LOOPS 


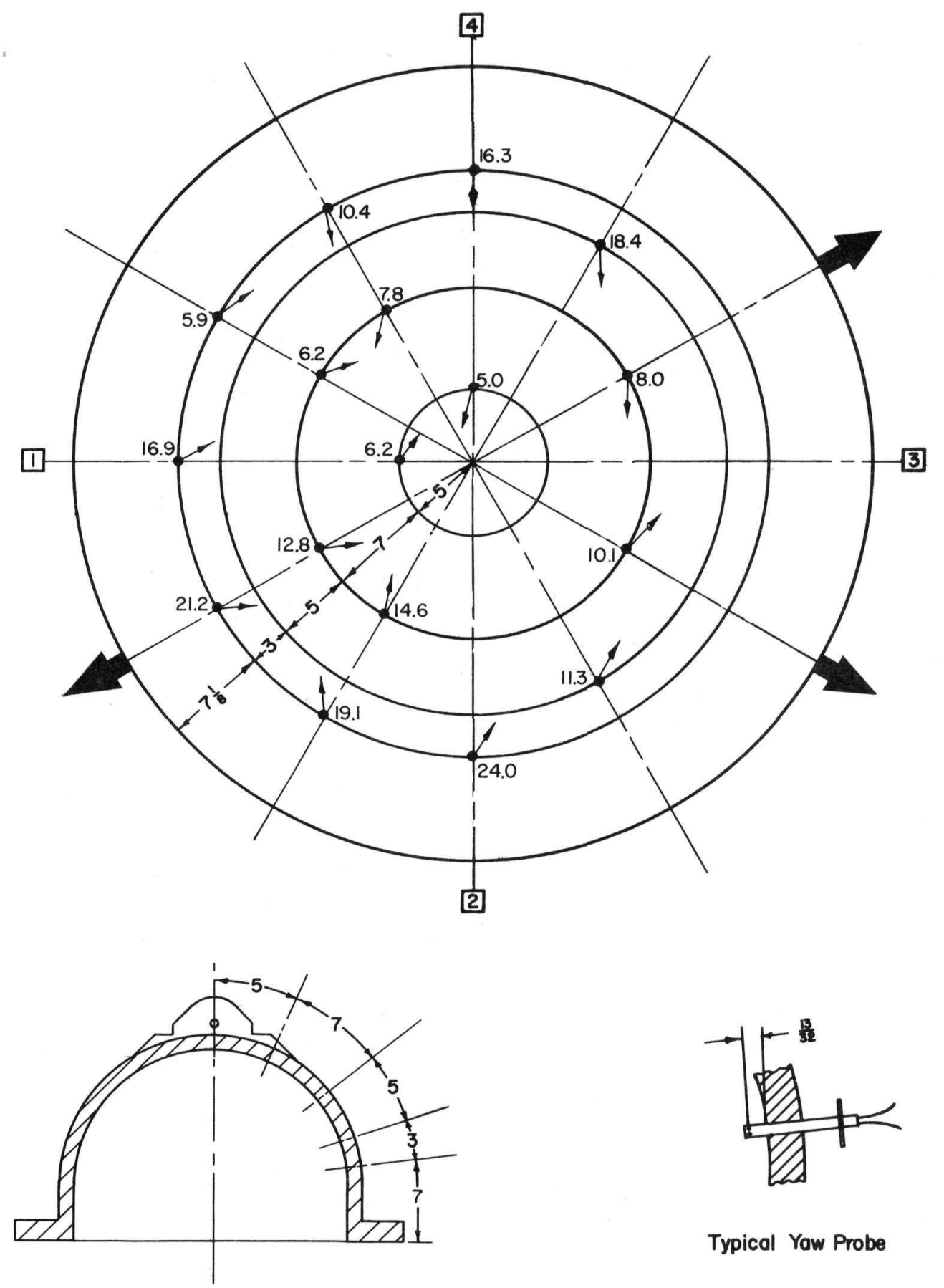

Typical Yaw Probe

Yaw-Probe Hole Locations

FIGURE 26. VELOCITIES AND DIRECTIONS OF FLOW AT THE INNER SURFACE OF THE UPPER DOME WITH HOLD-DOWN BARREL NO. 2 FOR OPERATION WITH THREE LOOPS

Arrows indicate flow direction, and numbers indicate velocity. 


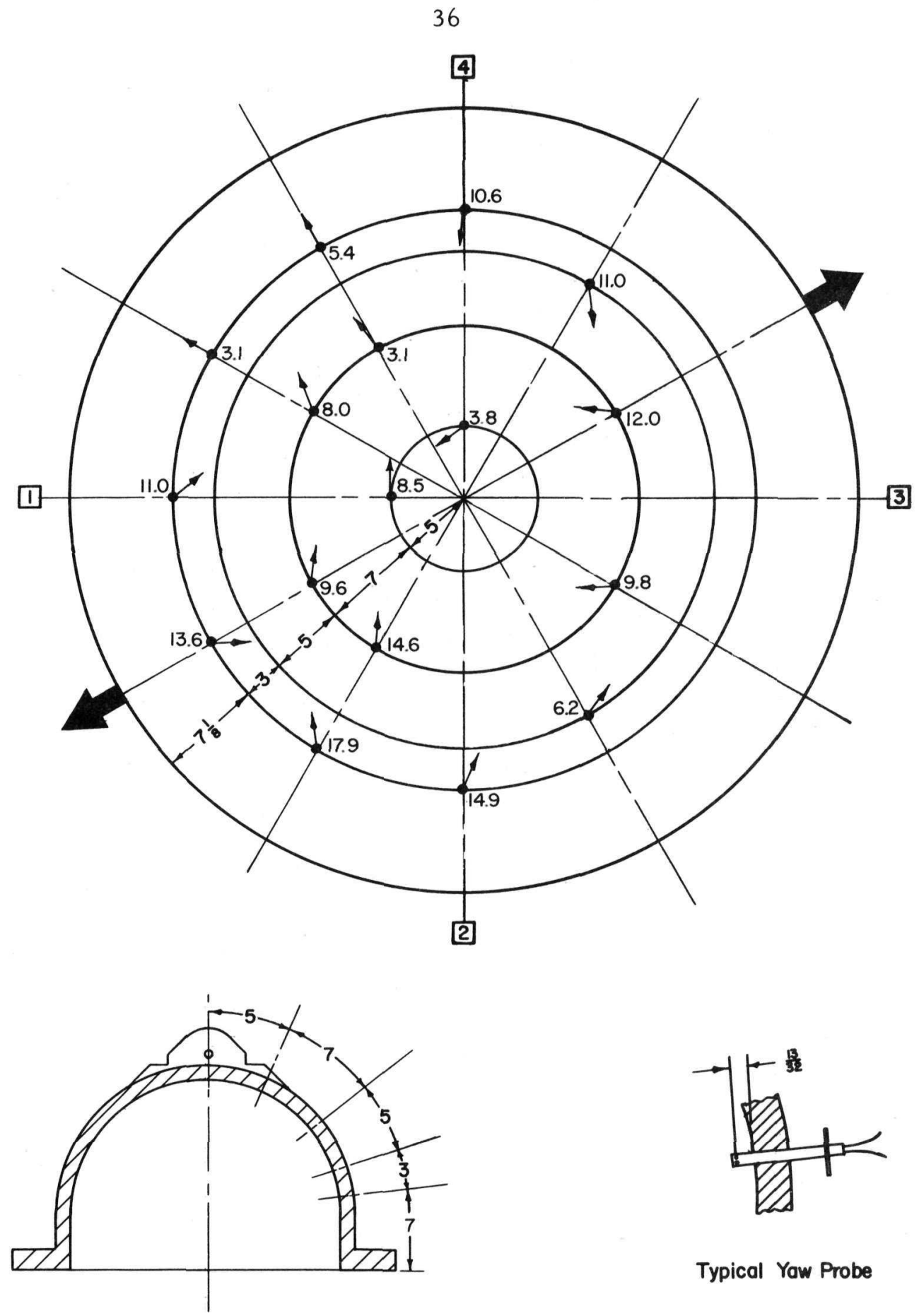

Typical Yaw Probe

Yaw-Probe Hole Locations

FIGURE 28. VELOCITIES AND DIRECTIONS OF FLOW AT THE INNER SURFACE OF THE UPPER DOME WITH HOLD-DOWN BARREL NO. 2 FOR OPERATION WITH TWO OPPOSED LOOPS

Arrows indicate flow direction, and numbers indicate velocity. 
Figure 29 is a development of Hold-Down Barrel No. 2 showing velocities and directions of flow in the space between the hold-down barrel and the pressure vessel of the model for operation with four loops. Velocities above the outlets ranged from 57 to $126 \mathrm{fps}$, and the lowest velocity observed, at the bottom of the passage, was $8.7 \mathrm{fps}$. At the bottom of the hold-down barrel it was found that there was considerable recirculation, with flow downward over the outer surface of the channel, and upward over the inner surface. The measurements shown in Figure 29 were taken 3/16-in. from the inner surface of the channel and, thus, show upward velocities at the bottom of the channel.

Figure 30 shows velocities and directions of flow for operation with three loops. Velocities above the outlets ranged from 36 to $119 \mathrm{fps}$, and the lowest velocity observed, at the bottom of the channel, was $7 \mathrm{fps}$.

Figure 31 shows velocities and directions of flow for operation with two adjacent loops. Velocities above the outlets ranged from 24 to $90 \mathrm{fps}$. The lowest velocity observed, at the bottom of the passage, was $4.9 \mathrm{fps}$.

Figure 32 shows velocities and directions of flow for operation with two opposed loops. Velocities above the outlets ranged from 28 to $93 \mathrm{fps}$, and the lowest velocity observed below the outlets was $7 \mathrm{fps}$. At one point, indicated in Figure 32, the flow direction fluctuated too rapidly to be determined with the yaw probe, but velocity appeared adequate.

Pressure Loss for Hold-Down Barrel No. 2

Pressure losses for flow from the upper plenum to a position $10 \mathrm{in}$. above the bottom of the hold-down barrel in the space between the hold-down barrel and the pressure vessel, were determined in the quarter-scale model for four-loop, threeloop, and two-loop operation. The static-pressure values were averages of data from points around the circumference of the model.

Values of pressure loss were divided by the velocity pressure computed from the open area of the annular slot at the top of the hold-down barrel minus the area of spacers. This gave a loss coefficient which can be multiplied by the computed velocity pressure to determine pressure loss under other conditions. For velocity-pressure computations it was assumed that 95.25 per cent of the flow passed through the opening at the top of the hold-down barrel. The loss was also expressed as a ratio of pressure los to velocity head in the model outlets, a more convenient velocity to calculate.

Using the se loss coefficients, pressure losses through the prototype hold-down barrel geometrically similar to Hold-Down Barrel No. 2 were computed. Values of pressure losses for the model, pressure losses for the prototype, and pressure-loss coefficients are tabulated below. 


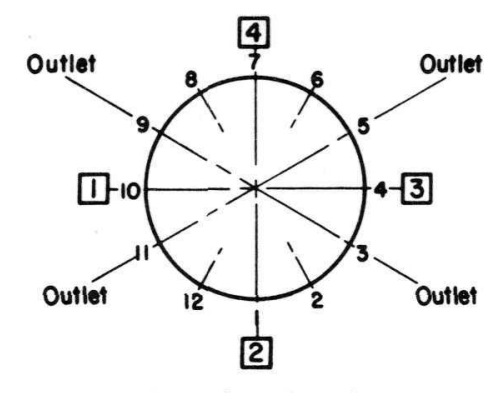

Orientation Sketch

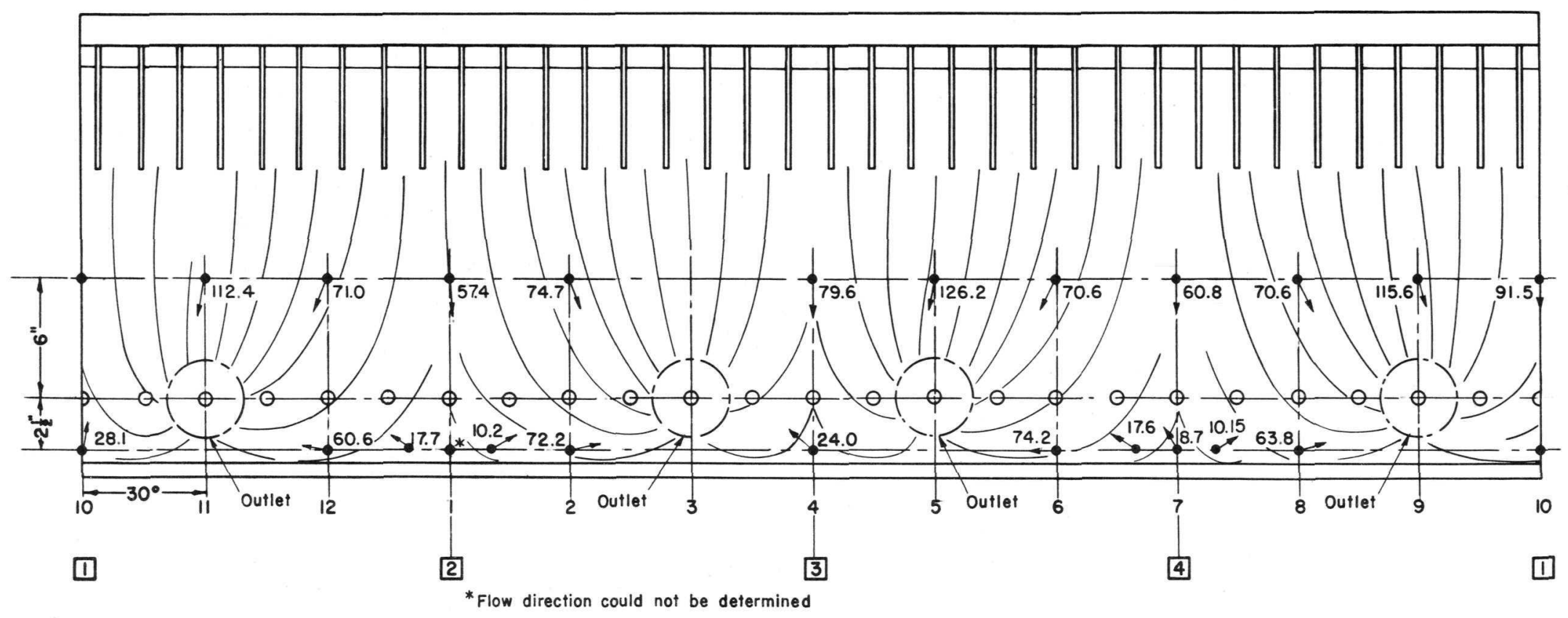

FIGURE 29. DIRECTIONS AND VELOCITIES OF FLOW IN THE ANNULAR SPACE BETWEEN HOLD-DOWN BARREL NO. 2 AND THE SHELL FOR OPERATION WITH FOUR LOOPS

Arrows indicate flow direction, and numbers indicate velocity. 


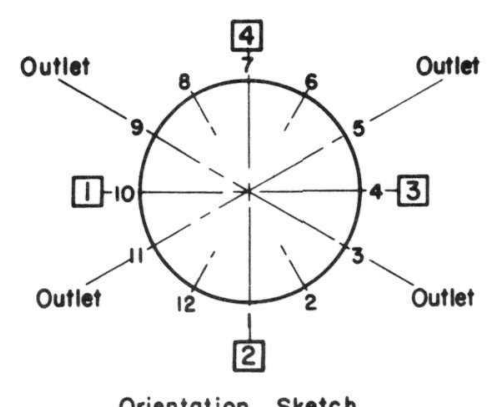

Orientation Sketch

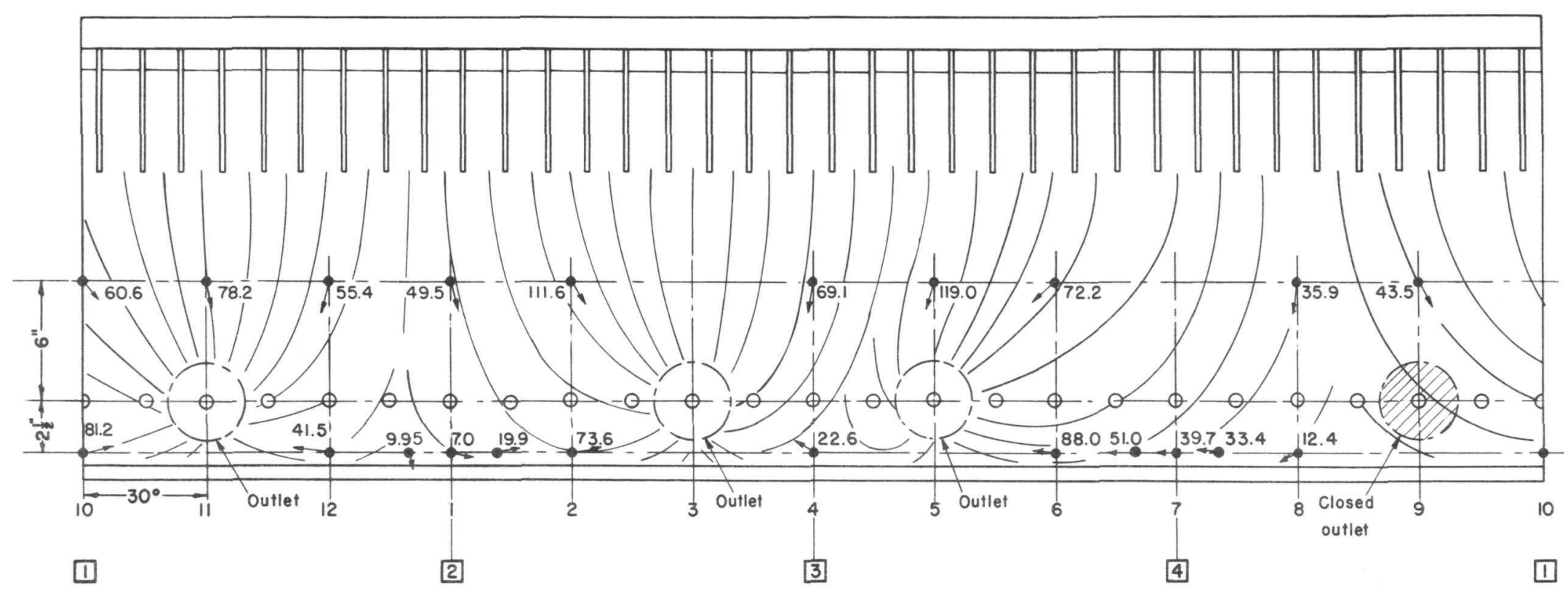

FIGURE 30. DIRECTIONS AND VELOCITIES OF FLOW IN THE ANNULAR SPACE BETWEEN HOLD-DOWN BARREL NO. 2 AND THE SHELL FOR OPERATION WITH THREE LOOPS

Arrows indicate flow direction, and numbers indicate velocity. 


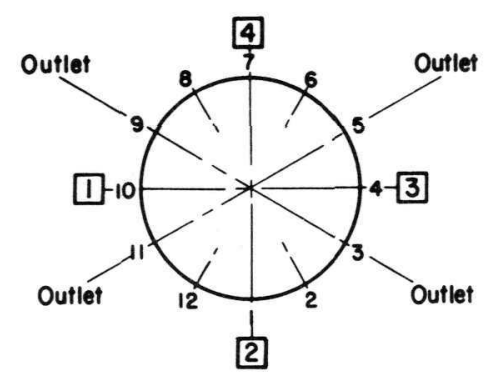

Orientation Sketch

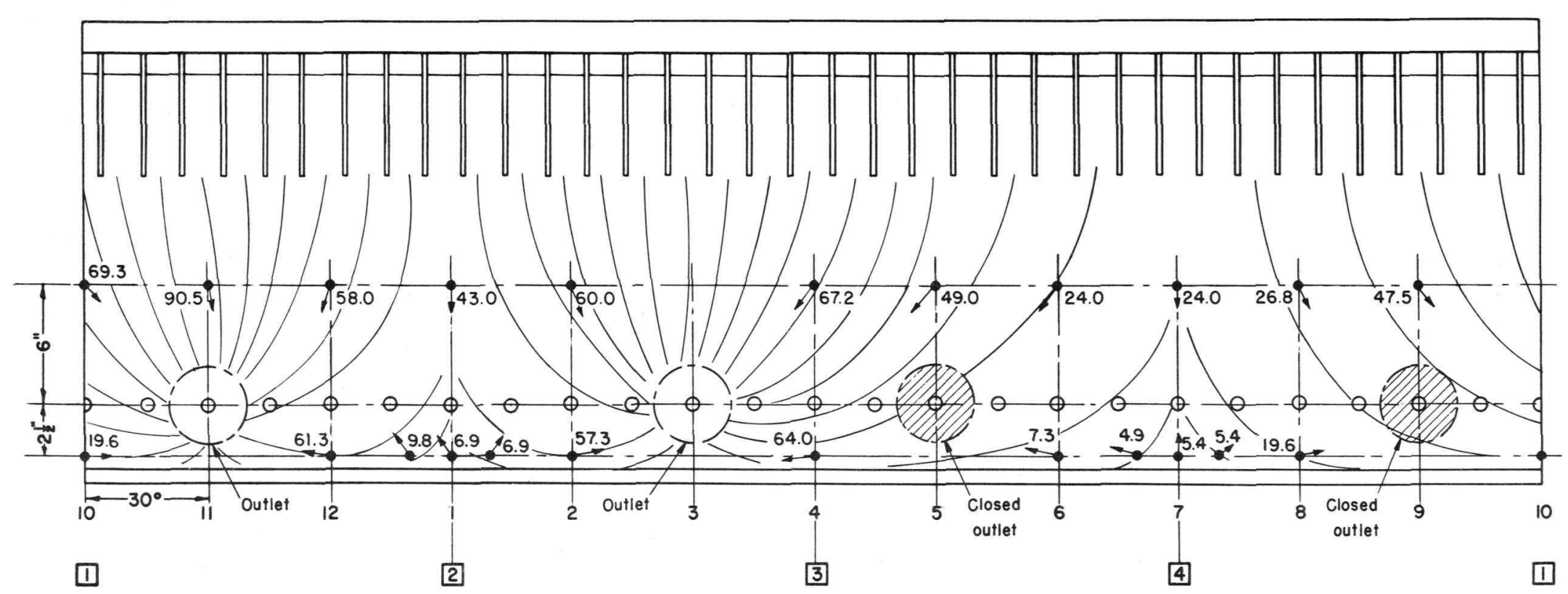

FIGURE 31. DIRECTIONS AND VELOCITIES OF FLOW IN THE ANNULAR SPACE BETWEEN HOLD-DOWN BARREL NO. 2 AND THE SHELL FOR OPERATION WITH TWO ADJACENT LOOPS

Arrows indicate flow direction, and numbers indicate velocity. 



\begin{tabular}{|c|c|c|c|c|}
\hline $\begin{array}{c}\text { Operating } \\
\text { Configuration }\end{array}$ & $\begin{array}{c}\text { Pressure Loss } \\
\text { in Quarter- } \\
\text { Scale Flow } \\
\text { Model, In. } \\
\text { of Water } \\
\end{array}$ & $\begin{array}{c}\text { Ratio of Pressure } \\
\text { Loss to Outlet- } \\
\text { Velocity Pressure }\end{array}$ & $\begin{array}{c}\text { Loss } \\
\text { Coefficient } \\
\end{array}$ & $\begin{array}{c}\text { Pressure Loss } \\
\text { Computed for } \\
\text { Prototype, } \\
\text { psi }\end{array}$ \\
\hline Four loops & 3.25 & 0.23 & 1.26 & 0.93 \\
\hline Three loops & 1.87 & 0.13 & 1. 24 & 0.61 \\
\hline Two adjacent loops & 1. 22 & 0.06 & 1.21 & 0.39 \\
\hline Two opposed loops & 1.16 & 0.06 & 1.21 & 0.39 \\
\hline
\end{tabular}

The variations in tabulated los s coefficient probably represent test error, and a value of 1.24 appears to best represent the loss.

Pressure Drop at Outlet Nozzle With Hold-Down Barrel No. 2

The pressure drop for flow from the space between the hold-down barrel and the shell, to a point ten diameters downstream from the outlet nozzle was determined. The inside diameter of the outlet pipe was $3.875 \mathrm{in.}$, and the diameter of the outlet nozzle was 3.75 in., so that a correction to place the data on the basis of a 3.75-in.-diameter outlet pipe was made.

The drop in total pressure expressed as a function of the velocity pressure was 0.36 velocity head based on velocity in the outlets for four-loop flow. For two-loop flow, the loss was lower, at 0.23 velocity head. The se values represent an irrecoverable loss in pressure.

The drop in static pressure, as measured, was 1.15 velocity heads for four-loop flow, and 1.05 velocity heads for two-loop flow, based on velocity in the outlet nozzle. When the se values were corrected for an outlet pipe diameter of 3.75 in., staticpressure drops of 1.30 and 1.17 velocity heads were obtained for four-loop and twoloop flow, respectively.

From the se values, the pressure loss through outlets of the prototype was computed. For both four-loop and two-loop flow, the drop in total pressure would be $1.5 \mathrm{psi}$, the drop in static pressure would be 5.2 and 7.7 psi, respectively.

\section{ACKNOW LEDGMENTS}

The work reported was performed by A. R. Orban and R. L. Johnston, under the supervision of Herbert R. Hazard. The work was done under WAPD Reference No. 73(14-452). Mr. Frank Grochowski, of Westinghouse Atomic Power Division, coordinated the work for Westinghouse and contributed much to the over-all planning of the research. His assistance is appreciated. 